\title{
1 Salicylic acid in plant salinity stress signalling and tolerance
}

2

3 Maheswari Jayakannan ${ }^{1,2,3}$, Jayakumar Bose ${ }^{2}$, Olga Babourina ${ }^{1}$, Zed Rengel ${ }^{1}$, and Sergey

4 Shabala ${ }^{2, *}$

$5{ }^{1}$ School of Earth and Environment, University of Western Australia, Perth, Australia;

$6{ }^{2}$ School of Land and Food and Tasmanian Institute for Agriculture, University of Tasmania,

7 Hobart, Australia; ${ }^{3}$ School of Biological Science, University of Tasmania, Hobart, Australia

$10 *$ Correspondence to:

11 Prof Sergey Shabala

12 School of Land and Food, University of Tasmania

13 Private Bag 54, Hobart, Tas 7001, Australia

14 Tel +613 62267539; E-mail: $\underline{\text { Sergey.Shabala@utas.edu.au }}$

15

16

17 Article type: Review paper

18 No. of Figures: 4

19 Original date of submission:

20 Running Title: Salicylic acid signaling during salt stress 21 


\section{Abstract}

23 Soil salinity is one of the major environmental stresses affecting crop production worldwide, costing over \$27Bln per year in lost opportunities to agricultural sector and making improved salinity tolerance of crops a critical step for sustainable food production. Salicylic acid (SA) is a signalling molecule known to participate in defence responses against variety of environmental stresses including salinity. However, the specific knowledge on how SA signalling propagates and promotes salt tolerance in plants remains largely unknown. This review focuses on the role of SA in regulation of ion transport processes during salt stress. In doing this, we briefly summarise a current knowledge on SA biosynthesis and metabolism, and then discuss molecular and physiological mechanisms mediating SA intracellular and long distance transport. We then discuss mechanisms of SA sensing and interaction with other plant hormones and signalling molecules such as ROS, and how this signalling affects activity of sodium and potassium transporters during salt stress. We argue that NPR1mediated SA signalling is pivotal for (i) controlling $\mathrm{Na}^{+}$entry into roots and the subsequent long-distance transport into shoots, (ii) enhancing $\mathrm{H}^{+}$-ATPase activity in roots, (iii) preventing stress-induced $\mathrm{K}^{+}$leakage from roots via depolarisation-activated potassium outward-rectifying channel (KOR) and ROS-activated non-selective cation channels (NSCC), and (iv) increasing $\mathrm{K}^{+}$concentration in shoots during salt stress. Future work should focus on how $\mathrm{SA}$ can regulate $\mathrm{Na}^{+}$exclusion and sequestration mechanisms in plants.

Key words: sodium; potassium; reactive oxygen species; intracellular ionic homeostasis; stomatal regulation; $\mathrm{H}^{+}$-ATPase; membrane transporters; voltage gating

\section{Abbreviations used:}

ABA - abscisic acid; aba3-1 - ABA biosynthesis mutant3-1; acd - accelerated cell death; agd2 - aberrant growth and death2; AHG2 -encoding poly (A)-specific ribonuclease; BA2Hbenzoic-acid-2-hydroxylase; cpr - constitutive expresser of PR; dnd - defence no death; eds enhanced disease susceptibility 5; GLR - glutamate receptor channels; GORK - Guard cells Outward-ㅌectifying depolarisation-activated $\underline{\mathrm{K}}^{+}$channel; HKT - high-affinity $\mathrm{K}^{+}$transporter; ICS- isochorismate synthase; IPL- isochorismate pyruvate lyase; isdl - lesions simulating disease 1; MeSAG- methyl salicylic acid O- $\beta$-glucose; MeSA-methyl salicylate; NahG naphthalene hydroxylase G; NPR1-non-expresser of PR proteins 1; NSCC - non-selective cation channels; nudt7 - nudix hydrolase7; PAL- ammonia-lyase; SABP2-SA-binding protein 
2; SAG- salicylic acid O- $\beta$-glucoside; SAGT-SA glycosyltransferase; SAR-systemic acquired resistance; SA-salicylic acid; SGE-salicyloyl glucose ester; sid2 -SA-induction-deficient; siz1 - small ubiquitin-like modifier E3 ligase1; snc1 - suppressor of npr1-1 consitutive1; SOS1 Salt overly sensitive1; SUMO -small ubiquitin-related modifier

\section{Introduction}

61

62

Agricultural crop production around the world is severely limited by a variety of abiotic (e.g. drought, salinity, acidity, flooding, temperature extremes) and biotic (pathogens) stresses. Salinity is one of the major abiotic stresses, affecting $7 \%$ of the world's total land area (Munns 2005) and imposing over \$27Bln penalties to agricultural sector every year (Qadir et al 2014). Salinisation of agricultural land is a continuing natural process, which is further exacerbated by secondary salinisation, resulting from poor irrigation and/or drainage practices. It is estimated that every day between 2000 and 4000 ha (Shabala 2013; Qadir et al 2014) of irrigated land in arid and semiarid areas across the globe are degraded by salinity and become unsuitable for crop production. This questions our ability to increase agricultural food production by $70 \%$ by 2050 to match the projected population growth to 9.3 billion (Tester and Langridge 2010; Shabala 2013). At the same time, remediation of salt-affected arable lands is very expensive and time consuming process that is hard to implement on a large scale. Thus, introducing salinity-tolerant cultivars through molecular and plant breeding is the most attractive and viable option to meet the ever-growing food demand (Ondrasek et al. 2011), that can be fulfilled if specific signalling events and/or mechanisms mediating salt tolerance are identified in plants.

Plants respond to any stress by initiating a broad range of signal transduction pathways. Among the signalling molecules, salicylic acid (SA; o-hydroxybenzoic acid; Fig. 1) has received a particular attention because of its capacity to regulate various aspects of plant responses to biotic and abiotic stresses through extensive signalling cross-talk with other growth substances (Horváth et al. 2007; Asensi-Fabado and Munné-Bosch 2011).

Apart from involvement in biotic stres responses (Vlot et al. 2009), SA has been shown to play a key role in defence responses against different abiotic stresses, including salinity and osmotic stress (Borsani et al. 2001). Impressive volume of studies have demonstrated that exogenous addition of SA can ameliorate toxicity symptoms induced by salinity stress in 
many plant species (reviewed in Horváth et al. 2007; Ashraf et al. 2010; Hayat et al. 2010). Moreover, various Arabidopsis mutants with altered SA synthesis and accumulation have been shown to have altered salt tolerance (Borsani et al. 2001; Cao et al. 2009; AsensiFabado and Munné-Bosch 2011; Miura et al. 2011; Hao et al. 2012). However, the exact signalling cascade and downstream mechanisms by which SA protects plants during salinity stress remain obscure. To shed light on this issue, the existing literature pertinent to SA biosynthesis, metabolism, transport, receptors and physiological roles in plants is reviewed in the following sections.

\section{SA biosynthesis}

SA is synthesised via two distinct pathways (Fig. 2): phenylalanine ammonia-lyase pathway and isochorismate pathway. The phenylalanine pathway occurs in the cytoplasm. In this pathway, SA is synthesised from phenylalanine (Fig. 1) after a series of reactions. In the first step, trans-cinnamic acid (Fig. 1) is produced from phenylalanine by the action of phenylalanine ammonia-lyase (PAL). Trans-cinnamic acid is subsequently converted to benzoic acid (Fig. 1) (Horváth et al. 2007; Mustafa et al. 2009). The enzyme benzoic-acid-2hydroxylase $(\mathrm{BA} 2 \mathrm{H})$ catalyses the final step that is the conversion of benzoic acid to SA. In rice seedlings, salinity increases endogenous SA levels by increasing BA2H activity, suggesting phenylalanine pathway is mediating endogenous SA elevation during salinity stress (Sawada et al. 2006).

The isochorismate pathway takes place in chloroplasts. In this pathway, SA is produced from chorismate (Fig. 1) via isochorismate (Fig. 1) as an intermediate product in a two-step process involving isochorismate synthase (ICS) and isochorismate pyruvate lyase (IPL) (Verberne et al. 2000; Strawn et al. 2007). The Arabidopsis genome encodes two ICS enzymes, namely, ICS1 (also known as SA-INDUCTION DEFICIENT2) and ICS2 (At1g18870). The mutants lacking functional ICS1 are severely compromised in SA accumulation. However, detection of residual SA in an ics $1 /$ ics 2 double mutant confirms that ICS pathway is not the only source of SA production in Arabidopsis (Garcion et al. 2008) and suggests that the phenylalanine ammonia-lyase pathway may be responsible for the residual SA in these mutants (Dempsey et al. 2011).

The bulk of pathogen-induced SA is synthesised by ICS1 in Arabidopsis, Nicotiana benthamiana and tomato (Wildermuth et al. 2001; Vlot et al. 2009), inducing local and 
117 systemic acquired resistance (SAR) in these plants (Wildermuth et al. 2001). Moreover, two 118 Arabidopsis mutants, SA-induction-deficient (sid)2-1(Nawrath and Metraux 1999) and 119 enhanced disease susceptibility (eds)16-1/sid2-2 (Dewdney et al. 2001) are defective in SA 120 biosynthesis and SAR, exhibiting enhanced susceptibility to disease. Subsequent analyses 121 showed that ICS1 enzymes are affected in these mutants (Wildermuth et al. 2001). 122 Interestingly, sid2-1 is also sensitive to UV light, ozone and salinity (Ogawa et al. 2005; 123 Dempsey et al. 2011), implying SA biosynthesis through isochorismate pathway is crucial for 124 abiotic stress tolerance in plants.

\section{2.1. Transcriptional and post-transcriptional regulation of SA biosynthesis}

126 The SA biosynthesis is controlled at both transcriptional and post-transcriptional levels. At transcriptional level, MYBs ( MY ELO BLAST; MYB 96 and MYB30), WRKYs (WRKY28 and WRKY 46) and WIPK(Wound-Induced Mitogen-Activated Protein Kinase)-activated transcription factors has been shown to positively regulate ICS gene encoding isochorismate synthase pathway thereby increasing SA production in plants (Vidhyasekaran 2015). At posttrancriptional level, the RNA-binding proteins (RBP) has been shown to participate in multiple post-transcriptional processes. In particular, an RBP from A. thaliana, AtRBPdefense related 1 (AtRBP-DR1) has been shown control ICS1-mediated SA biosynthesis, because (1) loss-of-function AtRBP-DRl mutant plants accumulated less SA and overexpression lines showed higher SA than wildtype; and (2) mRNA levels of SID2 were higher in AtRBP-DRl overexpressor lines (Qi et al . 2010).

\section{3. Metabolism of SA}

138 Most SA synthesised in plants is either glycosylated and/or methylated in the cells (Fig. 2).

139 The SA O- $\beta$-glucoside (SAG; Fig. 1) is the dominant glucosylated conjugate of SA, formed

140 by glucose conjugation at the hydroxyl group of SA, whereas glucose conjugation at the SA 141 carboxyl group produces salicyloyl glucose ester (SGE; Fig. 1) (Dean and Delaney 2008).

142 These glucose conjugation reactions are catalysed by SA glycosyltransferase (SAGT) that is 143 induced by exogenous application of SA or pathogen attack (Lee and Raskin 1998; Song 144 2006). SAGT has moderately high affinity for SA $\left(K_{m}=200 \mu \mathrm{M}\right)$ (Dempsey et al. 2011).

145 Arabidopsis encodes two SAGT enzymes: one favourably converts SA into SAG, whereas 146 the other enzyme may catalyse the formation of SGE from SA (Dean and Delaney 2008).

147 The SAGT appears to be located in the cytosol of tobacco plants (Dean et al. 2005). Further, 
148 SAG in Arabidopsis is thought to be produced in the cytosol and then actively transported 149 into the vacuole for storage. Several studies suggest that SAG is inactive and must be 150 converted to SA to induce defence responses (Dempsey et al. 2011). Indeed, SAG injection 151 into tobacco leaves induced expression of SA marker gene PR-1, however such expression is 152 preceded by the conversion of SAG into SA by the action of extracellular glycosidases 153 (Hennig et al. 1993). Moreover, a non-hydrolysable chemical analogue of SAG was unable to 154 induce PR-1 expression (Dempsey et al. 2011).

155 SA is metabolised into methyl salicylate (MeSA; Fig. 1) by the activity of salicylic acid carboxyl methyltransferase (SAMT1, $K_{m}=16 \mu \mathrm{M}$ ) at relatively low SA concentrations in vivo (Dempsey et al. 2011). Like SAG, MeSA is biologically inactive, and acts as a mobile endogenous signal carrier that triggers induction of SAR upon converting back into SA (Shulaev et al. 1997; Park et al. 2007; Vlot et al. 2008; Vlot et al. 2009; Manosalva et al. 2010). The MeSA can be further glucosylated into methyl salicylic acid O- $\beta$-glucose (MeSAG) (Song et al. 2008) (Fig. 2). Unlike SAG, the vacuole is not the predominant organelle for the storage of MeSAG, because MeSAG predominantly accumulates inside the cytosol (Fig. 2) (Dean et al. 2003; Dean et al. 2005).

The biological role of MeSAG remains unknown. One possible function is to serve as a nonvolatile storage form of MeSA (Dean et al. 2003; Dean et al. 2005) that can be released as MeSA during defence responses. Alternatively, formation of MeSAG may protect plant cells from toxicity caused by high concentration of intracellular MeSA formed during a defence response (Fig. 2).

169 A bacterial (Pseudomonas putida) salicylate hydroxylase enzyme, NahG (naphthalene 170 hydroxylase $G$ ) has been shown to degrade SA into catechol in plants (Gaffney et al. 1993). Indeed, transgenic NahG Arabidopsis, tobacco and rice plants (expressing Pseudomonas putida salicylate hydroxylase) have been used widely to demonstrate the crucial role of SA in plant responses to biotic and abiotic stresses (Yang et al. 2004; Kazemi et al. 2010). During salt stress, the germination of Arabidopsis $N a h G$ transgenic seeds was shown to be delayed (Rajjou et al. 2006), slightly accelerated (Lee et al. 2010) or completely unaffected by the salinity stress (Borsani et al. 2001). Moreover, NahG plants showed enhanced tolerance to salt and oxidative stresses (Borsani et al. 2001; Lee et al. 2010). The decreased NaCl-induced oxidative damage (Borsani et al. 2001; Cao et al. 2009) and antioxidant properties of catechol (Lee et al. 2010) have been suggested as the reasons for enhanced salt tolerance. However, a 
180

181

182

183

184

185

186

187

188

189

190

191

192

193

194

195

196

197

198

199

200

201

202

203

204

205

206

207

208

209

recent study reported that shoot growth of Arabidopsis $N a h G$ is sensitive to salt stress (Miura et al. 2011). Moreover, expression of $N a h G$ in Arabidopsis mutants with high endogenous SA decreased SA concentration, but the resulting phenotypes showed either a salt-sensitive (Miura et al. 2011) or a salt-tolerant response (Hao et al. 2012). Hence, a role of NahG in plants is unclear.

\section{SA transport in plants}

\subsection{Long-distance transport}

SA induces systemic acquired resistance (SAR) in plants and must be transported to other part of plant. This transport occurs in the phloem (Yalpani et al. 1991; Molders et al. 1996) and can be detected within minutes after SA application/induction (Ohashi et al. 2004). Among the various forms of SA, only the methylated form (MeSA) has been shown to travel in plant tissue locally as well as systemically after pathogen infections (Seskar et al. 1998). Thus, MeSA was considered to be the long-distance signalling molecule that moves from infected to uninfected leaves via phloem. Interestingly, MeSA also functions as airborne signal, with MeSA released from Pseudomonas syringae-infected Arabidopsis expressing OsSAMT (gene from rice), and tobacco mosaic virus-infected tobacco inducing defence genes in neighbouring plants (Shulaev et al. 1997). In addition, MeSA is the only form of SA that could pass through the tough cuticular layer by diffusion independently of cuticular $\mathrm{pH}$ (Niederl et al. 1998). Since MeSA is biologically inactive, MeSA does not activate any systemic defence response while being transported.

\subsection{Intracellular transport}

After biosynthesis, SA can be freely transported in and out of the cells, tissues and organs (Kawano et al. 2004). A radio-tracer study in tobacco cell suspension culture found de novo stimulation of free SA secretion across the plasma membrane (Chen 1999; Chen et al. 2001). This secretion was mediated by ROS- and $\mathrm{Ca}^{2+}$-dependent (at $200 \mu \mathrm{M} \mathrm{SA}$ ) and ROS- and $\mathrm{Ca}^{2+}$-independent (at $20 \mu \mathrm{M} \mathrm{SA}$ ) transporters (Chen 1999; Chen et al. 2001). However, the molecular identity of above transporters remains unknown. A volatile form of SA (MeSA) was shown to move between cells by diffusion (Shulaev et al. 1997).

In soybean, SAG transport into the vacuole (Fig. 2) was mediated by a tonoplast ABC transporter-like protein (Dean and Mills 2004), whereas tonoplast $\mathrm{H}^{+}$-antiporter was involved 
210 in tobacco suspension culture cells (Dean et al. 2005). Transporters mediating movements of

211 SA or SA conjugates between other cell organelles remain unknown (Fig. 2).

\section{5. SA receptors in plants}

213 To induce defence signalling, SA should bind to some specific receptors (Ross et al. 1999;

214 Forouhar et al. 2005). The search for SA receptors has resulted in identification of few SA-

215 binding proteins. Two enzymes controlling the balance between SA and MeSA were

216 suggested to act as SA receptors (Fig. 2): (i) SA methyl transferase 1 (SAMT1) that generates

217 MeSA from SA (Ross et al. 1999), and (ii) SA-binding protein 2 (SABP2) that is essential for

218 both local and systemic acquired resistance (SAR) following tobacco mosaic virus infection

219 (Kumar and Klessig 2003). This can be explained by the fact that SABP2 displays SA-

220 inhibiting methyl salicylate esterase activity to convert biologically inactive MeSA into

221 active SA (Forouhar et al. 2005). Subsequent studies reported that the activity of SAPB2 and

222 SAMT1 was essential for SAR signal perception in distal tissues (Park et al. 2009).

223 Interestingly, a transcriptomic-profiling study comparing wild halophytic tomato and a salt-

224 sensitive tomato cultivar revealed that SABP2 was induced by salinity only in wild tomato,

225 suggesting involvement of SABP2 in the salt tolerance mechanisms (Sun et al. 2010).

226 However, exact SABP2-mediated signalling during salt stress remains unknown.

227 Another SA receptor, NPR1 (non-expresser of PR proteins 1) emerged as a master regulatory

228 protein of SA-dependent defence responses by being a transcriptional co-activator of $P R$ -

229 gene expression (Vlot et al. 2009; Wu et al. 2012). Other studies reported that SA also binds

230 to NPR1 prologues NPR3 and NPR4 (Attaran and He 2012; Fu et al. 2012). At least two

231 forms of NPR1 exist in cells. An oligomeric NPR1 is the oxidised form localised in the

232 cytoplasm when the SA concentration is low (i.e., no infection/stress), but SA accumulation

233 following stress leads to an altered cellular redox status that in turn activates NPR1 by

234 reducing biologically-inactive NPR1 oligomers to active monomers (Dong 2004). SA binding

235 to NPR3 and NPR4 triggered reduction of oligomeric into monomeric NPR1 (Fu et al. 2012).

236 The resulting biologically-active NPR1 monomers are transported into the nucleus, where

237 they interact with specific transcription factors that activate SA-responsive $P R$ genes (Dong

238 2004; Fu et al. 2012). In fact, more than 90 percent of $P R$ genes were NPR1-dependent

239 (Blanco et al. 2009). In addition to regulating defence genes downstream of SA, the presence

240 of NPR1 in the nucleus is essential to prevent SA accumulation by inhibiting ICS1

241 (Wildermuth et al. 2001; Zhang et al. 2010). This is a crucial step in the SA signalling 
242 termination following successful induction of a defence response (Fig. 2). If SA accumulation

243 is not controlled that would lead to a hypersensitive response to stresses. Indeed, an

244 Arabidopsis nprl mutant accumulated excess SA (Zhang et al. 2010) and was defective in all

245 major SA-dependent defence responses (Cao et al. 1994; Delaney et al. 1995).

246 The role of NPR1 during salt stress is controversial because (1) Arabidopsis nprl mutant 247 showed enhanced growth during salt stress (Hao et al. 2012), and (2) NPR1248 hyperaccumulating Arabidopsis double mutant (npr3npr4) failed to undergo programmed cell 249 death (Attaran and $\mathrm{He}$ 2012; Fu et al. 2012), suggesting NPR1-mediated prevention of 250 programmed cell death may be beneficial during salt stress. The above observations suggest 251 that salt tolerance in plants can be controlled by both NPR1-independent and NPR1252 dependent mechanisms (Jayakannan et al. 2014).

\section{Physiological processes controlled by SA during salt stress}

\subsection{Seed germination}

255 Germination of Arabidopsis sid2 mutant defective in ICS1-mediated SA biosynthesis was 256 hypersensitive to salt stress (Lee et al. 2010). Reversal of salt-induced germination inhibition 257 was noted when the expression level of ICS1 was increased (Alonso-Ramirez et al. 2009). 258 The above results suggest SA synthesis and accumulation are vital for seed germination, 259 especially during salt stress. On the other hand, SA alone inhibited seed germination in 260 Arabidopsis (Nishimura et al. 2005; Lee et al. 2010), maize (Guan and Scandalios 1995) and 261 barley (Xie et al. 2007) in a dose-dependent manner. The above discrepancies seem to be 262 attributed to SA concentrations used in the above studies. For example, an inhibitory effect of 263 salt stress on germination of sid2 mutant was decreased when less than $50 \mu \mathrm{M}$ SA was 264 supplied exogenously, but inhibition was exaggerated when SA concentration exceeded 100 $265 \mu \mathrm{M}$ (Lee et al. 2010). Interestingly, a proteomic study involving SA-deficient NahG transgenic plants showed that germination of SA-deficient $N a h G$ plants was severely delayed under high salinity, but exogenous application of SA reversed this delayed germination of $N a h G$ (Rajjou et al. 2006). However, other studies reported that germination of NahG was not affected during salt stress (Borsani et al. 2001; Lee et al. 2010).

270 Regulation of ROS balance by SA has been suggested as a mechanism by which SA 271 modulates germination during salt stress (Lee et al. 2010). This may be true because SA and $272 \mathrm{H}_{2} \mathrm{O}_{2}$ form a "self-amplifying feedback loop" in response to various abiotic and biotic 
273 stresses; $\mathrm{H}_{2} \mathrm{O}_{2}$ induces accumulation of $\mathrm{SA}$, and SA enhances $\mathrm{H}_{2} \mathrm{O}_{2}$ concentration (Shirasu et 274 al. 1997; Rao and Davis 1999).

275

276

277

278

279

280

281

282

283

284

285

286

287

288

289

290

291

292

293

294

295

296

297

298

299

300

301

302

303

\subsection{Plant growth}

Effect of exogenous SA on growth is dependent on concentration and plant species. Usually, SA at relatively low concentrations (less than $100 \mu \mathrm{M}$ ) enhanced, and at relatively high concentrations (more than $1 \mathrm{mM}$ ) decreased, growth in diverse plant species (Rivas-San Vicente and Plasencia 2011). An alteration in the status of other hormones (Shakirova 2003) and/or photosynthesis, transpiration and stomatal conductance (Stevens et al. 2006) was suggested as a reason for the above effects.

Characterisation of Arabidopsis mutants with altered SA accumulation has provided direct evidence for the involvement of SA in plant growth. The SA-deficient plants [sid2, enhanced disease susceptibility 5 (eds5/sidl) and NahG] had higher biomass than wild type, whereas SA-hyperaccumulating mutants such as cpr1/5/6 (constitutive expresser of PR1/5/6), acd1/5/6/11 (accelerated cell death1/5/6/11), dnd1/2 (defence no death1/2), isd1 (lesions simulating disease1), nudt7 (nudix hydrolase7), agd2 (aberrant growth and death), snc1 (suppressor of npr1-1 consitutive1) and siz1 [SUMO (small ubiquitin-related modifier) E3 ligase1] showed dwarfism (reviewed in Miura et al. 2011; Rivas-San Vicente and Plasencia 2011). Negative regulation of cell division and cell enlargement by SA has been suggested as a reason for the above growth differences (Xia et al. 2009; Hao et al. 2012).

The growth of mutants with altered SA concentrations did not show any clear pattern during salt stress. Some studies have found that SA-deficient Arabidopsis NahG exhibited higher growth compared with the wild type and SA-hyperaccumulating (sncl) mutant during salinity stress (Borsani et al. 2001; Cao et al. 2009; Hao et al. 2012). However, in other studies SAhyperaccumulating mutants, namely siz1 (small ubiquitin-like modifier E3 ligase1) showed enhanced growth (Miura et al. 2011) and aba3-1 (ABA biosynthesis mutant3-1) showed no change in growth (Asensi-Fabado and Munné-Bosch 2011), whereas severe growth reduction was observed in SA-deficient plants (NahG, sid2 and eds5) during salt stress (Asensi-Fabado and Munné-Bosch 2011; Miura et al. 2011). Moreover, growth of NahG sizl double mutant was retarded (Miura et al. 2011), whereas NahG sncl had enhanced growth (Hao et al. 2012) during salt stress. Thus, more research is needed to decipher the exact role of SA in plant growth during salt stress. 


\subsection{Photosynthesis and transpiration}

305 An effect of exogenous SA on photosynthesis is concentration-dependent (Ashraf et al.

306

307

308

309

310

311

312

313

314

315

316

317

318

319

320

321

322

323

324

325

326

327

328

329

330

331

332

333

334

335

2010). At low concentrations (less than $10 \mu \mathrm{M}$ ), SA alleviated a salt-induced decrease in photosynthesis by increasing photosynthetic rate (Stevens et al. 2006; Nazar et al. 2011), carbon fixation, transpiration, stomatal conductance (Stevens et al. 2006; Poór et al. 2011a) and antioxidant activity (Szepesi et al. 2008) in many plant species. The opposite effects were noted at high (1-5 mM) SA concentrations (Nazar et al. 2011). Indeed, millimolar concentrations of SA decreased net photosynthetic rate (Nemeth et al. 2002), hampered synthesis of Rubisco (Pancheva and Popova 1997), decreased chlorophyll concentration (Moharekar et al. 2003), and resulted in an increase in chloroplast volume, swelling of thylakoid grana, and coagulation of stroma (Uzunova and Popova 2000). However, characterisation of Arabidopsis plants with altered endogenous SA concentration did not reveal any clear pattern. In one study, SA-deficient NahG showed higher chlorophyll concentration and variable-to-maximum fluorescence ratio $\left(F_{V} / F_{m}\right.$; indicator of damage to the PSII) in comparison with SA-hyperaccumulating sncl (Hao et al. 2012). In another study, there was no significant difference between SA-deficient (sid2 and eds5) and hyperaccumulating ( $a b a 3$ ) Arabidopsis mutants in chlorophyll concentration and $F v / F m$ ratio (Asensi-Fabado and Munné-Bosch 2011) during salt stress. Thus, more studies are needed to decipher the exact role of SA in influencing photosynthetic parameters during salt stress.

Stomata play a major role in processes involved in maintenance of photosynthetic capacity. In particular, stomatal closure and opening affect the transpiration and photosynthetic capacity, and thus plant adaptation to different stresses. Abscisic acid (ABA) is a phytohormone known to play an important role in stomatal closure and resistance to drought/water deficit. ABA affects stomatal closure through production of ROS species by NADPH oxidase (Acharya and Assmann 2009). SA antagonised the ABA-induced stomatal closure (Rai et al. 1986). However, $0.4 \mathrm{mM}$ SA induced stomatal closure in Arabidopsis within 2 h, decreasing stomatal gas exchange by 4-fold (Mateo et al. 2004; Rivas-San Vicente and Plasencia 2011). Specifically, the Arabidopsis wrky54wrky70 mutant, known to accumulate high levels of endogenous SA, exhibited tolerance to PEG-induced osmotic stress, which was correlated with improved water retention and enhanced stomatal closure ( $\mathrm{Li}$ et al. 2013). Moreover, bacteria-induced stomatal closure was not observed in SA-deficient $N a h G$ transgenic plants and SA-biosynthesis mutant eds16-2, indicating the essential role of 
336 SA in stomatal closure (Melotto et al. 2006; Melotto et al. 2008). The SA-induced stomatal 337 closure is also mediated by ROS that are generated in a reaction catalysed by peroxidase 338 instead of NADPH oxidase (Miura et al. 2013; Miura and Tada 2014). Interestingly, 339 Arabidopsis mutant with high endogenous SA concentration (sizl) showed decreased 340 stomatal aperture (Miura et al. 2013) and increased salt tolerance (Miura et al. 2011), 341 implying that SA-mediated stomatal closure may be beneficial during salt stress.

\section{$342 \quad 6.4$ Nutrient acquisition}

343 Exogenous application of SA is well known to ameliorate the effect of salinity. Some studies suggested maintenance of optimum $\mathrm{K}^{+} / \mathrm{Na}^{+}$ratio under saline conditions as a reason for enhanced salt tolerance in plants (reviewed in Horváth et al. 2007; Ashraf et al. 2010; Hayat et al. 2010). Usually, exogenous SA minimises $\mathrm{Na}^{+}$uptake while increasing tissue concentrations of $\mathrm{K}^{+}, \mathrm{Ca}^{2+}, \mathrm{Mg}^{2+}$ (Gunes et al. 2005; Yildirim et al. 2008), $\mathrm{Fe}^{2+}, \mathrm{Mn}^{2+}, \mathrm{Cu}^{2+}$ (El-Tayeb 2005; Gunes et al. 2005; Yildirim et al. 2008), P (El-Tayeb 2005; Gunes et al. 2005; Yildirim et al. 2008), N (Gunes et al. 2007; Yildirim et al. 2008; Nazar et al. 2011) and S (Nazar et al. 2011) in many plant species. However, there are some contrary results as well. The exogenous application of SA decreased concentrations of $\mathrm{K}^{+}$and $\mathrm{P}$ in shoot and root tissues of maize (Gunes et al. 2007) and in barley shoots (El-Tayeb 2005) under salinity stress. Surprisingly, $\mathrm{Na}^{+}$and $\mathrm{Cl}^{-}$concentrations in salinised spinach roots and shoots were not affected by SA (Eraslan et al. 2008). Further, application of SA to tomato plants inhibited $\mathrm{K}^{+}$ uptake and increased $\mathrm{Na}^{+}$uptake (Szepesi et al. 2009). Hence, a role of SA in maintenance of ionic homeostasis under salinity stress is poorly understood.

357 Most of the results mentioned above are based on prolonged salt exposure (days to months).

358 Hence, the reported effects are likely to be indirect and strongly dependent on doses of SA used, plant species studied, intensity and duration of salt stress (reviewed in Horváth et al.

360 2007). Moreover, the critical role of SA in modulation of specific ion transporters in roots 361 during salt stress has been overlooked. Hence, relevant information regarding membrane transporters controlling $\mathrm{K}^{+}$homeostasis, $\mathrm{Na}^{+}$uptake and $\mathrm{Na}^{+}$redistribution during salt stress is reviewed in the following sections.

\section{SA signalling networks}




\section{1 Cross-talks with other plant hormones}

366 SA exerts its role in a variety of plant developmental processes via cross-talk with gibberellins, abscisic acid, jasmonic acid and ethylene (Yasuda et al. 2008; Alonso-Ramirez et al. 2009; Khan et al. 2014). Interestingly, exogenous application of gibberellins (50 $\mu \mathrm{M})$ under $\mathrm{NaCl}(150 \mathrm{mM})$ stress slightly improved germination of SA-deficient sid2 mutant (Alonso-Ramirez et al. 2009), implying gibberellins can offset SA deficiency. In general, SA is antagonistic to ABA during development of systemic acquired resistance (SAR); exogenous application of ABA hampered the induction of SAR, whereas activation of SAR by SA suppressed ABA signalling (Yasuda et al. 2008). In addition, AHG2 (encoding poly (A)-specific ribonuclease) controlled $\mathrm{ABA}$ sensitivity and promoted expression of SAinducible genes (Nishimura et al. 2005). On the other hand, SA and ABA play a similar role in stomatal closure, albeit through a different pool of ROS (see above), suggesting the interaction between SA and ABA may be either positive or negative depending on conditions. Recently, the Arabidopsis sizl mutant defective in SUMO (small ubiquitin-related modifier) E3 ligase showed ABA sensitivity, high SA accumulation and expression of SA-regulated genes (Lee et al. 2006; Miura et al. 2009). Moreover, high endogenous concentrations of SA in two ABA-sensitive mutants (aba3 and sizl) improved salt tolerance (Asensi-Fabado and Munné-Bosch 2011; Miura et al. 2011), implying that suppression of ABA signalling by SA is critical for salt tolerance.

\subsection{Cross-talks with Reactive Oxygen Species}

Redox homeostasis in plants is maintained by the appropriate balance between ROS generation and scavenging (Apel and Hirt 2004). In general, low concentrations of SA facilitate tolerance to abiotic stresses, whereas high concentrations induce oxidative stress due to exacerbated generation of ROS species, leading to cell death (Shirasu et al. 1997; Lee et al. 2010; Poór et al. 2011b; Miura and Tada 2014). Similar to SA, $\mathrm{H}_{2} \mathrm{O}_{2}$ (a ROS species) at low concentrations acts as a signalling molecule, inducing tolerance to several biotic and abiotic stresses, but at high concentrations triggers apoptosis-like and autophagic cell death (Love et al. 2008; Quan et al. 2008). A "self-amplifying feedback loop" concept (Fig. 3) has been proposed to explain the interaction between $\mathrm{SA}$ and $\mathrm{H}_{2} \mathrm{O}_{2}$ during various abiotic and biotic stresses; $\mathrm{H}_{2} \mathrm{O}_{2}$ induces accumulation of $\mathrm{SA}$, and $\mathrm{SA}$ increases $\mathrm{H}_{2} \mathrm{O}_{2}$ concentration (Shirasu et al. 1997; Harfouche et al. 2008). A $\mathrm{H}_{2} \mathrm{O}_{2}$-mediated increase in endogenous SA concentration can be explained by the catalytic activity of $\mathrm{H}_{2} \mathrm{O}_{2}$ on BA2H enzyme involved 
397 in the conversion of benzoic acid to SA (Dempsey and Klessig 1995). An increase in $\mathrm{H}_{2} \mathrm{O}_{2}$ concentration by SA is mediated via inhibition of catalase and ascorbate peroxidase enzymes through SA binding (Durner and Klessig 1995; Durner and Klessig 1996; Horváth et al. 2002).

All biotic and abiotic stresses are causally associated with increased ROS concentrations. Salt stress increases production of various forms of ROS, namely superoxide $\left(\mathrm{O}_{2}^{-}\right)$, singlet oxygen $\left({ }^{1} \mathrm{O}_{2}\right)$, hydrogen peroxide $\left(\mathrm{H}_{2} \mathrm{O}_{2}\right)$ and hydroxyl radical $\left({ }^{\circ} \mathrm{OH}\right)$ in plants (reviewed in Parida and Das 2005). The ROS are scavenged by enzymatic and/or non-enzymatic antioxidants to protect plants from prolonged salt stress (Bose et al. 2014). Indeed, salt stress tolerance in diverse plant species was positively correlated with increased efficiency of the antioxidative system (Horváth et al. 2007; Munns and Tester 2008; Ashraf et al. 2010). Exogenous SA application at physiologically relevant concentrations caused moderate stress by generating $\mathrm{H}_{2} \mathrm{O}_{2}$, which induced the anti-oxidative defence system including enzymatic (superoxide dismutase, catalase, ascorbate peroxidase and glutathione peroxidase) and nonenzymatic antioxidants (glutathione, ascorbic acid, carotenoids and tocopherols) during acclimation to salt stress (Durner and Klessig 1995; Durner and Klessig 1996; Gill and Tuteja 2010).

Interestingly, SA may generate ROS species in the photosynthetic tissues, thereby enhancing oxidative damage under salt stress. Indeed, salt-treated wild type plants showed necrotic lesions in shoot tissues, but these lesions were not observed in salt-treated SA-deficient NahG transgenic plants (Borsani et al. 2001; Hao et al. 2012). High ratios of glutathione to oxidised glutathione (GSH/GSSG) and ascorbic acid to dehydroascorbate (ASA/DHA) in NahG plants enhanced their antioxidant capacity to mitigate salt-induced oxidative stress (Borsani et al. 2001; Cao et al. 2009; Hao et al. 2012). However, high ratio of GSH/GSSG in rice NahG lines did not result in oxidative stress tolerance (Yang et al. 2004; Kusumi et al. 2006), questioning the above notion. Moreover, SA-hyperaccumulating mutants, namely sizl (small ubiquitin-like modifier E3 ligase1) and aba3-1 (ABA biosynthesis mutant3-1) showed enhanced salt tolerance (Asensi-Fabado and Munné-Bosch 2011; Miura et al. 2011), implying high SA may be essential in preventing salt-induced oxidative stress. A subsequent comparison of two SA hyper accumulating Arabidopsis mutants namely nudt7 (contains the constitutively expressed SA-mediated NPR1-independent and NPR1-dependent defence genes) and nprl-5 (formerly known as sail, salicylic acid-insensitive1; without the SA- 
429 mediated NPR1-dependent defence response) under salt and oxidative stress revealed that 430 presence of NPR1-mediated SA signalling pathway is essential for salt-induced in vivo $\mathrm{H}_{2} \mathrm{O}_{2}$ 431 production as well as salt and oxidative stress tolerance (Jayakannan et al. 2014).

\section{SA-mediated control of $\mathrm{Na}^{+}$uptake and sequestration}

\subsection{Sodium transport across the plasma membrane}

434 Several transporters contribute to $\mathrm{Na}^{+}$uptake during salt stress. High-affinity potassium 435 transporters (HKT) have been reported in many plant species (Rubio et al. 1995; Gassmann et 436 al. 1996; Garciadeblas et al. 2003; Horie et al. 2006; Munns et al. 2012) and involved in both 437 high-affinity $\mathrm{Na}^{+}$uptake (Haro et al 2010) and $\mathrm{Na}^{+}$redistribution within the plant (Munns et 438 al 2012). Interestingly, SA pre-treatment in the Arabidopsis wild type (Jayakannan et al. 439 2013) and high endogenous-SA mutant nudt7 decreased the shoot $\mathrm{Na}^{+}$concentration during 440 prolonged salt stress (Jayakannan et al. 2014). Considering that another mutant with high SA 441 content (nprl-5) accumulated higher $\mathrm{Na}^{+}$in shoot than the wild type and showed 442 hypersensitivity to salt stress, it is clear that the NPR1-dependent SA signalling is critical for 443 salt tolerance by restricting $\mathrm{Na}^{+}$into the shoots (Fig. 4) (Jayakannan et al. 2014). However, it 444 remains unclear whether prevention of $\mathrm{Na}^{+}$loading into the shoots or enhanced $\mathrm{Na}^{+}$removal 445 from xylem responsible for lower $\mathrm{Na}^{+}$in shoots.

446 Exogenous SA pre-treatment for $1 \mathrm{~h}$ did not cause any significant difference in $\mathrm{Na}^{+}$influx during the acute salt stress in Arabidopsis roots (Jayakannan et al. 2013). Among the constitutively high endogenous SA Arabidopsis mutants, nudt7 recorded lowest $\mathrm{Na}^{+}$influx and the NPR1-signalling blockage mutant nprl-5 recorded the highest $\mathrm{Na}^{+}$influx (Jayakannan et al. 2014). The above observations suggest that the exogenous SA require longer than $1 \mathrm{~h}$ to act on $\mathrm{Na}^{+}$transporters, and the $\mathrm{SA}$ action occurs at post-transcriptional level because absence of NPR1 (a transcriptional co-activator of SA genes) has resulted in highest $\mathrm{Na}^{+}$influx and salt hypersensitivity (Jayakannan et al. 2014). As aforementioned studies have measured net $\mathrm{Na}^{+}$fluxes, it is hard to pinpoint whether SA inhibited $\mathrm{Na}^{+}$entry pathways and/or enhanced the activity of $\mathrm{Na}^{+} / \mathrm{H}^{+}$exchangers (Fig. 4). Additional experiments are needed to address this issue.

Weakly voltage-dependent non-selective cation channels (NSCC) are considered to be the main pathway for $\mathrm{Na}^{+}$entry into roots exposed to high $\mathrm{NaCl}$ concentrations (Tyerman et al. 1997; Amtmann and Sanders 1999; Tyerman and Skerrett 1999; Davenport and Tester 2000; 
460 Horie et al. 2001; Tyerman 2002; Tester and Davenport 2003; Horie and Schroeder 2004;

461 Horie et al. 2006). There are two sub groups within the NSCC channels that can mediate $\mathrm{Na}^{+}$ 462 uptake in plants: cyclic-nucleotide-gated channels and glutamate receptor-like channels 463 (GLRs). The latter may be suggested as possible downstream targets of SA. Indeed, salt 464 stress increased the glutamate synthase activity in tomato leaves (Berteli et al. 1995), and 465 exogenous SA modulated glutamate dehydrogenase activity in maize roots (Jain and 466 Srivastava 1981). Thus, it is plausible to suggest that SA can modulate GLRs involved in $\mathrm{Na}^{+}$ 467 entry and redistribution in plants.

468 A low cytosolic $\mathrm{Na}^{+}$concentration is maintained by the $\mathrm{Na}^{+} / \mathrm{H}^{+}$antiporter (SOS1 -SALT 469 OVERLY SENSITIVE1) that extrudes excess $\mathrm{Na}^{+}$from the cytosol (Hasegawa et al. 2000; 470 Sanders 2000; Shi et al. 2000; Zhu 2002, 2003) (Fig. 4). SOS1 promoter activity has been 471 identified in virtually all tissues, but the greatest activity is found in root epidermal cells, 472 particularly at root tips and in the cells bordering the vascular tissue. SOS1 plays three major 473 roles: (i) mediates $\mathrm{Na}^{+}$efflux from cytosol to the rhizosphere, (ii) increases the time available 474 for $\mathrm{Na}^{+}$storage in the vacuole by slowing down $\mathrm{Na}^{+}$accumulation in the cytoplasm, and (iii) 475 controls long-distance $\mathrm{Na}^{+}$transport between roots and shoots through $\mathrm{Na}^{+}$retrieval (Zhu 476 2003). The inherent stability of SOS1 mRNA was poor, with the half-life of only 10 minutes 477 (Chung et al. 2008). In a SOS1-overexpresser line this stability was increased by $\mathrm{H}_{2} \mathrm{O}_{2}$ in a 478 rapid (within $30 \mathrm{~min}$ ) concentration-dependent manner, but not by SA. This is surprising 479 because SA controls $\mathrm{H}_{2} \mathrm{O}_{2}$ balance via a "self-amplifying feedback loop" in plants (see 480 above; Fig. 3). Hence, more research is needed to decipher role of SA in SOS1 expression 481 and functioning in plants, if any (Fig. 4).

482 A stress-inducible plasma membrane localised PMP3 (PLASMA MEMBRANE PROTEIN 3) 483 has been shown to participate in $\mathrm{Na}^{+}$efflux dependent on a $\mathrm{Na}^{+} / \mathrm{H}^{+}$exchanger (Fig. 4) or $\mathrm{Na}^{+}-$ 484 ATPase during salt stress (Inada et al. 2005; Mitsuya et al. 2005). The PMP3 homologues 485 have been identified in a few halophyte monocotyledons, rice and Arabidopsis (Inada et al. 486 2005; Mitsuya et al. 2005; Chang-Qing et al. 2008). In situ hybridisation study in a halophyte 487 sheep grass (Aneurolepidium chinense) has revealed that AcPMP3 is localised in root cap and 488 root epidermis (Inada et al. 2005). Interestingly, AcPMP3 expression was up-regulated within 48915 min of $\mathrm{H}_{2} \mathrm{O}_{2}$ and 30 min of SA treatments (Inada et al. 2005), implying SA may control 490 AcPMP3 operation during salt stress. 


\subsection{Sodium transport across the tonoplast}

492 Vacuolar $\mathrm{Na}^{+}$sequestration is important for the maintenance of low cytosolic $\mathrm{Na}^{+}$ 493 concentrations and is considered as a key attribute of salinity tolerance mechanism employed 494 by salt tolerant species, including halophytes (Shabala 2013). This sequestration is mediated 495 by tonoplast $\mathrm{Na}^{+} / \mathrm{H}^{+}$exchangers (NHX) (Apse et al. 1999; Gaxiola et al. 1999) that belong to 496 the CPA family of cation/proton antiporters (Apse and Blumwald 2007; Rodríguez-Rosales et 497 al. 2008). At least six NHX isoforms have been found in Arabidopsis; with their expression 498 pattern, both tissue- and stress-specific (Rodríguez-Rosales et al. 2009). NHX exchangers are 499 constititively expressed in halophytes and and inducible in salt-tolerant glycophyte species 500 (Shabala and Mackay 2011). Overexpression of NHX1 increased salinity tolerance of 501 Arabidopsis (Apse et al. 1999), Brassica napus (Zhang et al. 2001), tomato (Zhang and 502 Blumwald 2001) and maize (Zörb et al. 2005). These results confirm that increased capacity 503 for vacuolar $\mathrm{Na}^{+}$sequestration is important for salinity tolerance. Interestingly, AtNHX1 and 504 AtNHX2 can mediate $\mathrm{K}^{+}$transport along with $\mathrm{Na}^{+} / \mathrm{H}^{+}$exchange (Zhang and Blumwald 2001; 505 Apse et al. 2003; Bassil et al. 2011; Barragán et al. 2012). While there is no direct proof of 506 SA regulating NHXs, the NHX1 expression was upregulated by ABA and/or SA treatments 507 in diverse plant species (Wu et al. 2004; Guan et al. 2011). Further, SA interacts with ABA 508 during abiotic stresses (see below). Hence, it may be possible that SA may regulate $\mathrm{Na}^{+}$and $509 \mathrm{~K}^{+}$vacuolar sequestration through NHXs.

\section{9. Membrane transporters controlling $\mathbf{K}^{+}$homeostasis during salt stress}

511 Salinity stress operates through ionic, hyperosmotic and oxidative components that severely 512 hamper cell metabolism. All these components affect ion transport processes, particularly $\mathrm{K}^{+}$ 513 uptake and retention. Under salt conditions, entry of $\mathrm{Na}^{+}$ions causes $\mathrm{K}^{+}$leakage, thereby 514 depleting the cytosolic $\mathrm{K}^{+}$pool available for metabolic functions, which eventually leads to cell death (Shabala and Cuin 2008; Shabala 2009). Thus, maintenance of $\mathrm{K}^{+}$homeostasis has

516 emerged as a fundamental component of salt tolerance mechanism (Maathuis and Amtmann 517 1999; Shabala and Cuin 2008; Demidchik et al. 2010). Indeed, several studies reported a 518 strong positive correlation between the capacity of roots to retain $\mathrm{K}^{+}$and salt tolerance in 519 barley (Chen et al. 2005; Chen et al. 2007a; Chen et al. 2007b), wheat (Cuin et al. 2008), 520 lucerne (Smethurst et al. 2008) and Arabidopsis (Shabala et al. 2005; Shabala et al. 2006; 521 Jayakannan et al. 2011; Bose et al. 2013; Jayakannan et al. 2013). Moreover, divalent cations 522 (Shabala et al. 2003; Shabala et al. 2006), polyamines (Pandolfi et al. 2010) and compatible 
523 solutes (Cuin and Shabala 2005; Cuin and Shabala 2007) were able to prevent NaCl-induced $524 \mathrm{~K}^{+}$loss and improve salt tolerance. In several plant species, SA ameliorated detrimental 525 effects of salinity ( Horváth et al. 2007; Ashraf et al. 2010; Hayat et al. 2010) and increased $526 \mathrm{~K}^{+}$concentration in roots ( $\mathrm{He}$ and Zhu 2008), but it remained unclear whether enhanced $\mathrm{K}^{+}$ 527 uptake or prevention of $\mathrm{K}^{+}$loss played a major role in this ameliorative effect. Recent work 528 in our laboratory have proved that prevention of salt-induced $\mathrm{K}^{+}$loss through $\mathrm{K}^{+}$-outward 529 rectifying channel (Fig. 4) plays a major role in SA mediated salt tolerance in plants 530 (Jayakannan et al. 2013).

531 In many species, $\mathrm{NaCl}$-induced $\mathrm{K}^{+}$efflux from mesophyll is mediated by depolarisationactivated outward-rectifying $\mathrm{K}^{+}$channels (GORK in Arabodopsis)(Shabala and Cuin 2008;

533 Anshutz et al 2014). Interestingly, pre-treating Arabidopsis roots with physiologically 534 relevant concentration of SA $(<0.5 \mathrm{mM})$ has decreased $\mathrm{K}^{+}$leak through GORK channel (Fig. 535 4) suggesting prevention of $\mathrm{K}$ loss through GORK is the main mode of action for SA during 536 salt stress (Jayakannan et al. 2013). Further, decreased $\mathrm{K}^{+}$leak through GORK channel is 537 NPR1 mediated because nprl-5 mutant unable to decrease $\mathrm{K}^{+}$loss through depolarisation538 activated KOR channel (Jayakannan et al. 2014).

539 Being a voltage-gated channel, GORK operation is strongly affected by the plasma 540 membrane $\mathrm{H}^{+}$-ATPase that plays a crucial role in regulating membrane potential (Palmgren and Nissen 2010). The activation of proton pumps by salt stress (Kerkeb et al. 2001) is positively correlated with salinity tolerance, and this effect is stronger in salt-tolerant than salt-sensitive species (Chen et al. 2007b; Sahu and Shaw 2009; Bose et al. 2013; Jayakannan 544 et al. 2013). Such an increase in $\mathrm{H}^{+}$pumping could act in two parallel pathways. First, enhanced activity of $\mathrm{H}^{+}$-ATPase would down-regulate depolarisation-activated outwardrectifying $\mathrm{K}^{+}$channels, thus preventing $\mathrm{K}^{+}$leakage via KOR channels (Chen et al. 2007b). Indeed, the SA pre-treatment under salinity conditions enhanced the $\mathrm{H}^{+}$-ATPase activity in a dose- and time-dependent manner (Fig. 4), helping plants to maintain membrane potential at more negative values thereby decreasing $\mathrm{NaCl}$-induced $\mathrm{K}^{+}$leakage via depolarizationactivated KOR channels in Arabidopsis (Jayakannan et al. 2013). Interestingly, the above SA effects were absent in $n p r 1-5$ mutant but present in $n u d t 7$ mutant, implying SA up-regulates $\mathrm{H}^{+}$-ATPAse activity through NPR1 (Jayakannan et al. 2014). Secondly, $\mathrm{H}^{+}$pumping would

553 provide a driving force for the plasma membrane $\mathrm{Na}^{+} / \mathrm{H}^{+}$exchanger (SOS1) to remove $\mathrm{Na}^{+}$ 554 from the cytoplasm to the apoplast (Shi et al. 2000; Apse and Blumwald 2007), thus 
555 decreasing $\mathrm{Na}^{+} / \mathrm{K}^{+}$ratio in the cytoplasm. The SA pre-treatment increased the activity of the 556 plasma membrane $\mathrm{H}^{+}$-ATPase in grape and peas during temperature stress (Liu et al. 2008; 557 Liu et al. 2009); hence, each of the two pathways mentioned above may potentially be 558 affected by SA. Overall, it appears that beneficial effects of SA during salt stress may be 559 related to up-regulation of the plasma membrane $\mathrm{H}^{+}$-ATPase activity and the consequent 560 effects on intracellular ionic homeostasis of $\mathrm{Na}^{+}$and $\mathrm{K}^{+}$.

561 Another major pathway of $\mathrm{K}^{+}$leak from the cytosol under saline condition is via ROSactivated $\mathrm{K}^{+}$permeable channels (Shabala and Pottosin 2014; Anschutz et al 2014). Various ROS species are produced during salt stress in various cellular compartments including apoplast, chloroplasts (in leaves) and mitochondria (reviewed in Miller et al. 2009). Some of these ROS species ( $\mathrm{OH}$ and $\mathrm{H}_{2} \mathrm{O}_{2}$ ) can activate either GORK or NSCC channels to induce $\mathrm{K}^{+}$loss and trigger programmed cell death during salt stress (e.g Shabala et al. 2007; Demidchik et al. 2010; Poór et al. 2011b). Hence, prevention of $\mathrm{K}^{+}$loss through ROSactivated NSCC during salt stress is critical for salt tolerance in plants. Given the reported cross-talks between SA and ROS signalling pathways (see below), SA can control $\mathrm{K}^{+}$loss though ROS-activated NSCC (Fig. 4). Indeed, the results from two Arabidopsis mutants with high endogenous SA concentration and altered SA signalling (nudt7 and npr1-5) demonstrated that SA decreased the oxidative damage and hypersensitivity to oxidative stress only if NPR1 was present (Jayakannan et al. 2014). The above conclusion is proposed based on the fact that nprl-5 mutant showed higher $\mathrm{K}^{+}$efflux and higher sensitivity during ROS stress than nudt7 mutant (Jayakannan et al. 2014).

\section{Conclusions and future work}

578 Exogenous application of SA is widely used as a possible remedy to ameliorate toxicity symptoms induced by salinity stress in many plant species (Horváth et al. 2007; Ashraf et al. 2010). Also popular is an idea of overexpressing SA biosynthesis through isochorismate synthase (ICS) pathway and NPR1 in glycophytes. Yet, neither of these methods has fully negated detrimental effects of salinity on plant performance. Several reasons may contribute to this.

584 First, similar to other signalling molecules (such as cytosolic free $\mathrm{Ca}^{2+}, \mathrm{H}_{2} \mathrm{O}_{2}$, or $\mathrm{NO}$ ) salicylic acid signalling is highly dynamic and should be considered in a strict temporal context. This condition is often not met. In this context, a constitutive overexpression of SA 
587 biosynthesis may interfere with other signal transduction pathways negating all the beneficial effects gained. Can we talk about stress-specific SA "signatures", in a manner similar to those reported for cytosolic free $\mathrm{Ca}^{2+}$ (Dodd et al 2010) or $\mathrm{H}_{2} \mathrm{O}_{2}$ (Bose et al 2014a)? This aspect warrants proper investigation in a future.

591 The NPR1 mediated SA signalling not only improve salt tolerance but also offer tolerance to 592 many biotic and abiotic stresses and, thus, may be considered as an important part of the 593 cross-tolerance mechanism. However, as shown above NPR1-dependent SA signalling may control numerous physiological traits by (i) minimising $\mathrm{Na}^{+}$entry into roots and the subsequent long-distance transport into shoots, (ii) enhancing $\mathrm{H}^{+}$-ATPase activity in roots, (iii) preventing stress-induced $\mathrm{K}^{+}$leakage from roots via depolarisation-activated $\mathrm{KOR}$ and ROS-activated non-selective cation channels (NSCC), and (iv) increasing $\mathrm{K}^{+}$concentration in shoots under salt and oxidative stresses. Each of these traits, however, should be considered in a context of the tissue specificity. Salinity stress tolerance is a physiologically multi-

600 faceted trait, and the latter are not always mutually compatible. Say, reduced $\mathrm{Na}^{+}$entry into

601 roots and lesser $\mathrm{Na}^{+}$accumulation in the shoot (Jayakannan et al 2013) will jeopardise the 602 plant's ability to adjust to hyperosmotic conditions imposed by salinity. Thus SA-mediated $603 \mathrm{Na}^{+}$reduction from uptake should be complemented by plant's ability to achieve osmotic adjustment by increase de novo synthesis of compatible solutes.

605 The energy cost of some of above enhanced traits should be also not neglected. It was 606 reported before that both halophytes (Bose et al 2014b) and salt-tolerant glycophytes cultivars 607 (Chen et al 2007b) have intrinsically higher rate of $\mathrm{H}^{+}$pumping and thus are able to maintain 608 more negative membrane potential, preventing $\mathrm{NaCl}$-induced $\mathrm{K}^{+}$loss via GORK channels. 609 However, this comes with the yield penalties. Thus, a constitutive enhancement of SA 610 production and associated increase in root $\mathrm{H}^{+}$-pumping (Jayakannan et al 2013) may result in 611 reduced plant yield under control conditions. Thus, enhanced SA biosynthesis through either 612 isochorismate synthase (ICS) and NPR1 pathways should be achieved only by using stress613 inducible promoters, to avoid associated yield penalties resulting from (otherwise futile) $\mathrm{H}^{+}$ 614 pumping to maintain highly negative membrane potential.

615

616 Acknowledgement

617 Maheswari Jayakannan is a recipient of Australian Postgraduate Award (APA) and 618 University of Western Australia Postgraduate Award (UPA). This work was supported by the 
619 Australian Research Council grants to Z. Rengel (DP0988193 \& DP130104825) and S. 620 Shabala (DP0987402 \& DP1094663).

621

622 


\section{References}

624

625 Acharya BR, Assmann SM (2009) Hormone interactions in stomatal function. Plant Mol Biol 626 69: 451-462

627 Alonso-Ramirez A, Rodriguez D, Reyes D, Jimenez JA, Nicolas G, Lopez-Climent M, 628 Gomez-Cadenas A, Nicolas C (2009) Evidence for a role of gibberellins in salicylic acid629 modulated early plant responses to abiotic stress in Arabidopsis seeds. Plant Physiol 150: $630 \quad 1335-1344$

631 Amtmann A, Sanders D (1999) Mechanisms of $\mathrm{Na}^{+}$uptake by plant cells. Adv Bot Res 29: $632 \quad 75-112$

633 Apel K, Hirt H (2004) Reactive oxygen species: metabolism, oxidative stress, and signal 634 transduction. Annu Rev Plant Biol 55: 373-399

635 Apse MP, Aharon GS, Snedden WA, Blumwald E (1999) Salt tolerance conferred by 636 overexpression of a vacuolar $\mathrm{Na}^{+} / \mathrm{H}^{+}$antiport in Arabidopsis. Science 285: 1256-1258

637 Apse MP, Blumwald E (2007) $\mathrm{Na}^{+}$transport in plants. FEBS Lett 581: 2247-2254

638 Apse MP, Sottosanto JB, Blumwald E (2003) Vacuolar cation/ $\mathrm{H}^{+}$exchange, ion homeostasis, 639 and leaf development are altered in a T-DNA insertional mutant of AtNHX1, the 640 Arabidopsis vacuolar $\mathrm{Na}^{+} / \mathrm{H}^{+}$antiporter. Plant J 36: 229-239

641 Asensi-Fabado M, Munné-Bosch S (2011) The aba3-1 mutant of Arabidopsis thaliana 642 withstands moderate doses of salt stress by modulating leaf growth and salicylic acid levels. 643 J Plant Growth Regul 30: 456-466

644 Ashraf M, Akram NA, Arteca RN, Foolad MR (2010) The physiological, biochemical and 645 molecular roles of brassinosteroids and salicylic acid in plant processes and salt tolerance. 646 Crit Rev Plant Sci 29: 162-190

647 Attaran E, He SY (2012) The long-sought-after salicylic acid receptors. Molecular Plant 5: $648 \quad 971-973$ 
649 Barragán V, Leidi EO, Andrés Z, Rubio L, De Luca A, Fernández JA, Cubero B, Pardo JM 650 (2012) Ion exchangers NHX1 and NHX2 mediate active potassium uptake into vacuoles to 651 regulate cell turgor and stomatal function in Arabidopsis. The Plant Cell 24: 1127-1142

652 Bassil E, Tajima H, Liang Y-C, Ohto M-a, Ushijima K, Nakano R, Esumi T, Coku A, 653 Belmonte M, Blumwald E (2011) The Arabidopsis $\mathrm{Na}^{+} / \mathrm{H}^{+}$antiporters NHX1 and NHX2 654 control vacuolar $\mathrm{pH}$ and $\mathrm{K}+$ homeostasis to regulate growth, flower development, and 655 reproduction. The Plant Cell 23: 3482-3497

656 Berteli F, Corrales E, Guerrero C, Ariza MJ, Pliego F, Valpuesta V (1995) Salt stress 657 increases ferredoxin-dependent glutamate synthase activity and protein level in the leaves of 658 tomato. Physiol Plant 93: 259-264

659 Blanco F, Salinas P, Cecchini N, Jordana X, Hummelen P, Alvarez M, Holuigue L (2009) 660 Early genomic responses to salicylic acid in Arabidopsis. Plant Mol Biol 70: 79-102

661 Borsani O, Valpuesta V, Botella MA (2001) Evidence for a role of salicylic acid in the 662 oxidative damage generated by $\mathrm{NaCl}$ and osmotic stress in Arabidopsis seedlings. Plant 663 Physiol 126: 1024-1030

664 Bose J, Rodrigo-Moreno A, Shabala S (2014a) ROS homeostasis in halophytes in the context 665 of salinity stress tolerance. J Exp Bot 65: 1241-1257

666 Rapid regulation of the plasma membrane H+-ATPase activity contributes to salinity 667 tolerance in two halophyte species, Atriplex lentiformis and Chenopodium quinoa

668 Bose J, Rodrigo-Moreno A, Lai D, Xie Y, Shen W, Shabala S (2014b) Rapid regulation of 669 the plasma membrane $\mathrm{H}^{+}$-ATPase activity is essential to salinity tolerance in two halophyte 670 species, Atriplex lentiformis and Chenopodium quinoa. Ann Bot (in press; 671 10.1093/aob/mcu219)

672 Bose J, Xie Y, Shen W, Shabala S (2013) Haem oxygenase modifies salinity tolerance in 673 Arabidopsis by controlling $\mathrm{K}^{+}$retention via regulation of the plasma membrane $\mathrm{H}^{+}$-ATPase 674 and by altering SOS1 transcript levels in roots. J Exp Bot 64: 471-481

675 Cao H, Bowling SA, Gordon AS, Dong X (1994) Characterization of an Arabidopsis mutant 676 that is nonresponsive to inducers of systemic acquired resistance. Plant Cell 6: 1583-1592 
677 Cao Y, Zhang ZW, Xue LW, Du JB, Shang J, Xu F, Yuan S, Lin HH (2009) Lack of salicylic 678 acid in Arabidopsis protects plants against moderate salt stress. Zeitschrift fur 679 Naturforschung C, Journal of Biosciences 64: 231-238

680 Chang-Qing Z, Shunsaku N, Shenkui L, Tetsuo T (2008) Characterization of two plasma 681 membrane protein 3 genes (PutPMP3) from the alkali grass, Puccinellia tenuiflora, and 682 functional comparison of the rice homologues, OsLti6a/b from rice. Biochemistry and 683 Molecurar Biology Reports 41: 448-454

684 Chen H-J (1999) $\mathrm{Ca}^{2+}$-dependent excretion of salicylic acid in tobacco cell suspension 685 culture. Botanical Bulletin of Academia Sinica 40: 267-273

686 Chen H-J, Hou W-C, Kuc J, Lin Y-H (2001) $\mathrm{Ca}^{2+}$ dependent and $\mathrm{Ca}^{2+}$ independent excretion 687 modes of salicylic acid in tobacco cell suspension culture. J Exp Bot 52: 1219-1226

688 Chen Z, Cuin TA, Zhou M, Twomey A, Naidu BP, Shabala S (2007a) Compatible solute 689 accumulation and stress-mitigating effects in barley genotypes contrasting in their salt 690 tolerance. J Exp Bot 58: 4245-4255

691 Chen Z, Newman I, Zhou M, Mendham N, Zhang G, Shabala S (2005) Screening plants for 692 salt tolerance by measuring $\mathrm{K}^{+}$flux: a case study for barley. Plant Cell Environ 28: 1230$693 \quad 1246$

694 Chen Z, Pottosin II, Cuin TA, Fuglsang AT, Tester M, Jha D, Zepeda-Jazo I, Zhou M, 695 Palmgren MG, Newman IA, Shabala S (2007b) Root plasma membrane transporters 696 controlling $\mathrm{K}^{+} / \mathrm{Na}^{+}$homeostasis in salt-stressed barley. Plant Physiol 145: 1714-1725

697 Chung JS, Zhu JK, Bressan RA, Hasegawa PM, Shi H (2008) Reactive oxygen species 698 mediate $\mathrm{Na}^{+}$-induced SOS1 mRNA stability in Arabidopsis. Plant J 53: 554-565

699 Cuin T, Shabala S (2007) Amino acids regulate salinity-induced potassium efflux in barley $700 \quad$ root epidermis. Planta 225: 753-761

701 Cuin TA, Betts SA, Chalmandrier R, Shabala S (2008) A root's ability to retain $\mathrm{K}^{+}$correlates 702 with salt tolerance in wheat. J Exp Bot 59: 2697-2706

703 Cuin TA, Shabala S (2005) Exogenously supplied compatible solutes rapidly ameliorate $704 \mathrm{NaCl-induced} \mathrm{potassium} \mathrm{efflux} \mathrm{from} \mathrm{barley} \mathrm{roots.} \mathrm{Plant} \mathrm{Cell} \mathrm{Physiol} \mathrm{46:} \mathrm{1924-1933}$ 
705 Davenport RJ, Tester M (2000) A weakly voltage-dependent, nonselective cation channel mediates toxic sodium influx in wheat. Plant Physiol 122: 823-834

707 Dean JV, Delaney SP (2008) Metabolism of salicylic acid in wild-type, ugt74f1 and ugt74f2

708 glucosyltransferase mutants of Arabidopsis thaliana. Physiol Plant 132: 417-425

709 Dean JV, Mills JD (2004) Uptake of salicylic acid 2-O- $\beta$-D-glucose into soybean tonoplast 710 vesicles by an ATP-binding cassette transporter-type mechanism. Physiol Plant 120: 603-612

711 Dean JV, Mohammed LA, Fitzpatrick T (2005) The formation, vacuolar localization, and 712 tonoplast transport of salicylic acid glucose conjugates in tobacco cell suspension cultures. 713 Planta 221: 287-296

714 Dean JV, Shah RP, Mohammed LA (2003) Formation and vacuolar localization of salicylic 715 acid glucose conjugates in soybean cell suspension cultures. Physiol Plant 118: 328-336

716 Delaney TP, Friedrich L, Ryals JA (1995) Arabidopsis signal transduction mutant defective 717 in chemically and biologically induced disease resistance. Proc Natl Acad Sci 92: 6602-6606

718 Demidchik V, Cuin TA, Svistunenko D, Smith SJ, Miller AJ, Shabala S, Sokolik A, Yurin V 719 (2010) Arabidopsis root $\mathrm{K}^{+}$-efflux conductance activated by hydroxyl radicals: single720 channel properties, genetic basis and involvement in stress-induced cell death. J Cell Sci 721 123: $1468-1479$

722

Dempsey DA, Klessig DF (1995) Signals in plant disease resistance. Bulletin de l'Institut 723 Pasteur 93: 167-186

724 Dempsey DMA, Vlot AC, Wildermuth CM, Klessig FD (2011) Salicylic acid biosynthesis 725 and metabolism. The Arabidopsis Book 9: e0156 doi:0110.1199/tab.0156

726 Dewdney J, Reuber TL, Wildermuth MC, Devoto A, Cui J, Stutius LM, Drummond EP, 727 Ausubel FM (2001) Three unique mutants of Arabidopsis identify eds loci required for 728 limiting growth of a biotrophic fungal pathogen. Plant J 24: 205-218

729 Dodd AN, Kudla J, Sanders D (2010) The language of calcium signaling. Annu Rev Plant $730 \quad$ Biol 61: 593-620

731 Dong X (2004) NPR1, all things considered. Curr Opin Plant Biol 7: 547-552 
732 Durner J, Klessig DF (1995) Inhibition of ascorbate peroxidase by salicylic acid and 2, 6-

733 dichloroisonicotinic acid, two inducers of plant defense responses. Proc Natl Acad Sci 92:

$734 \quad 11312-11316$

735 Durner Jr, Klessig DF (1996) Salicylic acid is a modulator of tobacco and mammalian 736 catalases. J Biol Chem 271: 28492-28501

737 El-Tayeb MA (2005) Response of barley grains to the interactive effect of salinity and 738 salicylic acid. Plant Growth Regul 45: 215-224

739 Eraslan F, Inal A, Pilbeam DJ, Gunes A (2008) Interactive effects of salicylic acid and silicon 740 on oxidative damage and antioxidant activity in spinach (Spinacia oleracea L. cv. Matador) 741 grown under boron toxicity and salinity. Plant Growth Regul 55: 207-219

742 Forouhar F, Yang Y, Kumar D, Chen Y, Fridman E, Park SW, Chiang Y, Acton TB, 743 Montelione GT, Pichersky E (2005) Structural and biochemical studies identify tobacco 744 SABP2 as a methyl salicylate esterase and implicate it in plant innate immunity. Proc Natl $745 \quad$ Acad Sci 102: 1773-1778

746 Fu ZQ, Yan S, Saleh A, Wang W, Ruble J, Oka N, Mohan R, Spoel SH, Tada Y, Zheng N 747 (2012) NPR3 and NPR4 are receptors for the immune signal salicylic acid in plants. Nature 748 486: 228-232

749 Gaffney T, Friedrich L, Vernooij B, Negrotto D, Nye G, Uknes S, Ward E, Kessmann H, 750 Ryals J (1993) Requirement of salicylic acid for the induction of systemic acquired 751 resistance. Science 261: 754-756

752 Garciadeblas B, Senn ME, Banuelos MA, Rodriguez-Navarro A (2003) Sodium transport and 753 HKT transporters: the rice model. Plant J 34: 788-801

754 Garcion C, Lohmann A, Lamodiere E, Catinot J, Buchala A, Doermann P, Metraux J-P 755 (2008) Characterization and biological function of the ISOCHORISMATE SYNTHASE2 756 gene of Arabidopsis. Plant Physiol 147: 1279-1287

757 Gassmann W, Rubio F, Schroeder JI (1996) Alkali cation selectivity of the wheat root high758 affinity potassium transporter HKT1. Plant J 10: 869-882 
759 Gaxiola RA, Rao R, Sherman A, Grisafi P, Alper SL, Fink GR (1999) The Arabidopsis 760 thaliana proton transporters, AtNhxl and Avpl, can function in cation detoxification in yeast. $761 \quad$ Proc Natl Acad Sci 96: 1480-1485

762 Gill SS, Tuteja N (2010) Reactive oxygen species and antioxidant machinery in abiotic stress 763 tolerance in crop plants. Plant Physiol Biochem 48: 909-930

764 Guan B, Hu Y, Zeng Y, Wang Y, Zhang F (2011) Molecular characterization and functional 765 analysis of a vacuolar $\mathrm{Na}^{+} / \mathrm{H}^{+}$antiporter gene (HcNHX1) from Halostachys caspica. Mol 766 Biol Rep 38: 1889-1899

767 Guan L, Scandalios JG (1995) Developmentally related responses of maize catalase genes to 768 salicylic acid. Proc Natl Acad Sci 92: 5930-5934

769 Gunes A, Inal A, Alpaslan M, Eraslan F, Bagci EG, Cicek N (2007) Salicylic acid induced 770 changes on some physiological parameters symptomatic for oxidative stress and mineral 771 nutrition in maize (Zea mays L.) grown under salinity. J Plant Physiol 164: 728-736

772 Gunes A, Inal A, M.Alpaslan, Cicek N, Guneri E, Eraslan F, Guzelordu T (2005) Effects of 773 exogenously applied salicylic acid on the induction of multiple stress tolerance and mineral nutrition in maize (Zea mays L.). Arch Agron Soil Sci 51: 687-695

775

776

777

778

779

780

781

782

Hao L, Zhao Y, Jin D, Zhang L, Bi X, Chen H, Xu Q, Ma C, Li G (2012) Salicylic acidaltering Arabidopsis mutants response to salt stress. Plant Soil 354: 81-95

Harfouche AL, Rugini E, Mencarelli F, Botondi R, Muleo R (2008) Salicylic acid induces $\mathrm{H}_{2} \mathrm{O}_{2}$ production and endochitinase gene expression but not ethylene biosynthesis in Castanea sativa in vitro model system. J Plant Physiol 165: 734-744

Hasegawa PM, Bressan RA, Zhu JK, Bohnert HJ (2000) Plant cellular and molecular responses to high salinity. Annu Rev Plant Physiol Plant Mol Biol 51: 463-499

Hayat Q, Hayat S, Irfan M, Ahmad A (2010) Effect of exogenous salicylic acid under changing environment: A review. Environ Exp Bot 68: 14-25

He Y, Zhu Z (2008) Exogenous salicylic acid alleviates $\mathrm{NaCl}$ toxicity and increases antioxidative enzyme activity in Lycopersicon esculentum. Biologia Plantarum 52: 792-795 
786 Hennig J, Malamy J, Grynkiewicz G, Indulski J, Klessig DF (1993) Interconversion of the salicylic acid signal and its glucoside in tobacco. Plant J 4: 593-600

Horie T, Horie R, Chan WY, Leung HY, Schroeder JI (2006) Calcium regulation of sodium hypersensitivities of $\operatorname{sos} 3$ and athkt1 mutants. Plant Cell Physiol 47: 622-633

790

Horie T, Schroeder JI (2004) Sodium transporters in plants. Diverse genes and physiological functions. Plant Physiol 136: 2457-2462 transporters with different properties of $\mathrm{Na}^{+}$and $\mathrm{K}^{+}$transport in Oryza sativa. Plant $\mathrm{J}$ 27: 129-138

795

796

797

798

799

800

801

802

803

804

805

806

807

808

809

810

811

812

Horváth E, Janda T, Szalai G, Páldi E (2002) In vitro salicylic acid inhibition of catalase activity in maize: differences between the isozymes and a possible role in the induction of chilling tolerance. Plant Sci 163: 1129-1135

Horváth E, Szalai G, Janda T (2007) Induction of abiotic stress tolerance by salicylic acid signaling. Journal of Plant Growth Regulation 26: 290-300

Inada M, Ueda A, Shi W, Takabe T (2005) A stress-inducible plasma membrane protein 3 (AcPMP3) in a monocotyledonous halophyte, Aneurolepidium chinense, regulates cellular $\mathrm{Na}^{+}$and $\mathrm{K}^{+}$accumulation under salt stress. Planta 220: 395-402

Jain A, Srivastava HS (1981) Effect of salicylic acid on nitrite reductase and glutamate dehydrogenase activities in maize roots. Physiol Plant 53: 285-288

Jayakannan M, Babourina O, Rengel Z (2011) Improved measurements of $\mathrm{Na}^{+}$fluxes in plants using calixarene-based microelectrodes. J Plant Physiol 168: 1045-1051

Jayakannan M, Bose J, Babourina O, Rengel Z, Shabala S (2013) Salicylic acid improves salinity tolerance in Arabidopsis by restoring membrane potential and preventing saltinduced $\mathrm{K}^{+}$loss via a GORK channel. J Exp Bot 64: 2255-2268

Jayakannan M, Bose J, Babourina O, Shabala S, Massart A, Poschenrieder C, Rengel Z (2014) NPR1-dependent salicylic acid signalling pathway is pivotal for enhanced salt and oxidative stress tolerance in Arabidopsis. J Exp Bot (accepeted) 
813 Kawano T, Furuichi T, Muto S (2004) Controlled salicylic acid levels and corresponding

814 signaling mechanisms in plants. Plant biotechnology 21:319-335

815 Kazemi N, Khavari-Nejad RA, Fahimi H, Saadatmand S, Nejad-Sattari T (2010) Effects of 816 exogenous salicylic acid and nitric oxide on lipid peroxidation and antioxidant enzyme

817 activities in leaves of Brassica napus L. under nickel stress. Scientia Horticulturae 126: 402$818 \quad 407$

819 Kerkeb L, Donaire JP, Rodríguez-Rosales MP (2001) Plasma membrane $\mathrm{H}^{+}$-ATPase activity 820 is involved in adaptation of tomato calli to $\mathrm{NaCl}$. Physiol Plant 111: 483-490

821 Khan MIR, Asgher M, Khan NA (2014) Alleviation of salt-induced photosynthesis and 822 growth inhibition by salicylic acid involves glycinebetaine and ethylene in mungbean (Vigna 823 radiata L.). Plant Physiology and Biochemistry 80: 67-74

824 Kumar D, Klessig DF (2003) High-affinity salicylic acid-binding protein 2 is required for 825 plant innate immunity and has salicylic acid-stimulated lipase activity. Science Signalling 826 100: 16101

827 Kusumi K, Yaeno T, Kojo K, Hirayama M, Hirokawa D, Yara A, Iba K (2006) The role of 828 salicylic acid in the glutathione-mediated protection against photooxidative stress in rice. 829 Physiol Plant 128: 651-661

830 Lee H-i, Raskin I (1998) Glucosylation of salicylic acid in Nicotiana tabacum Cv. Xanthi-nc. 831 Phytopathology 88: 692-697

832 Lee J, Nam J, Park HC, Na G, Miura K, Jin JB, Yoo CY, Baek D, Kim DH, Jeong JC (2006) 833 Salicylic acid-mediated innate immunity in Arabidopsis is regulated by SIZ1 SUMO E3 834 ligase. Plant J 49: 79-90

835 Lee S, Kim SG, Park CM (2010) Salicylic acid promotes seed germination under high 836 salinity by modulating antioxidant activity in Arabidopsis. New Phytol 188: 626-637

837 Li J, Besseau S, Törönen P, Sipari N, Kollist H, Holm L, Palva ET (2013) Defense-related 838 transcription factors WRKY70 and WRKY54 modulate osmotic stress tolerance by 839 regulating stomatal aperture in Arabidopsis. New Phytol 200: 457-472 
840 Liu Y, Liu H, Pan Q, Yang H, Zhan J, Huang W (2009) The plasma membrane $\mathrm{H}^{+}$-ATPase is

841 related to the development of salicylic acid-induced thermotolerance in pea leaves. Planta 842 229: $1087-1098$

843 Liu Y, Zhang J, Liu H, Huang W (2008) Salicylic acid or heat acclimation pre-treatment 844 enhances the plasma membrane-associated ATPase activities in young grape plants under 845 heat shock. Scientia Horticulturae 119: 21-27

846 Love AJ, Milner JJ, Sadanandom A (2008) Timing is everything: regulatory overlap in plant 847 cell death. Trends Plant Sci 13: 589-595

848 Maathuis FJM, Amtmann A (1999) $\mathrm{K}^{+}$nutrition and $\mathrm{Na}^{+}$toxicity: The basis of cellular $849 \quad \mathrm{~K}^{+} / \mathrm{Na}^{+}$ratios. Ann Bot 84: 123-133

850 Manosalva PM, Park S-W, Forouhar F, Tong L, Fry WE, Klessig DF (2010) Methyl esterase 8511 (StMES1) is required for systemic acquired resistance in potato. Mol Plant-Microbe 852 Interact 23: 1151-1163

853 Mateo A, Mühlenbock P, Rustérucci C, Chang CC-C, Miszalski Z, Karpinska B, Parker JE, 854 Mullineaux PM, Karpinski S (2004) LESION SIMULATING DISEASE 1 is required for 855 acclimation to conditions that promote excess excitation energy. Plant Physiol 136: 28188562830

857 Melotto M, Underwood W, He SY (2008) Role of stomata in plant innate immunity and 858 foliar bacterial diseases. Annu Rev Phytopathol 46: 101

859 Melotto M, Underwood W, Koczan J, Nomura K, He SY (2006) Plant stomata function in 860 innate immunity against bacterial invasion. Cell 126: 969-980

861 Miller G, Suzuki N, Ciftci-Yilmaz S, Mittler R (2009) Reactive oxygen species homeostasis 862 and signalling during drought and salinity stresses. Plant Cell Environ 33: 453-467

863 Mitsuya S, Taniguchi M, Miyake H, Takabe T (2005) Disruption of $R C I 2 A$ leads to over864 accumulation of $\mathrm{Na}^{+}$and increased salt sensitivity in Arabidopsis thaliana plants. Planta 222: $865 \quad 1001-1009$ 
866 Miura K, Lee J, Jin JB, Yoo CY, Miura T, Hasegawa PM (2009) Sumoylation of ABI5 by the 867 Arabidopsis SUMO E3 ligase SIZ1 negatively regulates abscisic acid signaling. Proc Natl 868 Acad Sci 106: 5418-5423

869 Miura K, Okamoto H, Okuma E, Shiba H, Kamada H, Hasegawa PM, Murata Y (2013) SIZ1

870 deficiency causes reduced stomatal aperture and enhanced drought tolerance via controlling 871 salicylic acid-induced ROS accumulation in Arabidopsis. Plant J 73: 91-104

872 Miura K, Sato A, Ohta M, Furukawa J (2011) Increased tolerance to salt stress in the 873 phosphate-accumulating Arabidopsis mutants siz1 and pho2. Planta 234: 1191-1199

874 Miura K, Tada Y (2014) Regulation of water, salinity, and cold stress responses by salicylic 875 acid. Frontiers in plant science 5: doi: 10.3389/fpls.2014.00004

876 Moharekar S, Lokhande S, Hara T, Tanaka R, Tanaka A, Chavan P (2003) Effect of salicylic 877 acid on chlorophyll and carotenoid contents of wheat and moong seedlings. Photosynthetica $878 \quad 41: 315-317$

879 Molders W, Buchala A, Metraux J-P (1996) Transport of salicylic acid in tobacco necrosis $880 \quad$ virus-infected cucumber plants. Plant Physiol 112: 787-792

881 Munns R (2005) Genes and salt tolerance: bringing them together. New Phytol 167: 645-663

882 Munns R, James RA, Xu B, Athman A, Conn SJ, Jordans C, Byrt CS, Hare RA, Tyerman 883 SD, Tester M, Darren Plett, Gilliham M (2012) Wheat grain yield on saline soils is improved 884 by an ancestral $\mathrm{Na}^{+}$transporter gene. Nat Biotechnol 30: 360-364

885 Munns R, Tester M (2008) Mechanisms of salinity tolerance. Annu Rev Plant Biol 59: 651$886 \quad 681$

887 Mustafa NR, Kim HK, Choi YH, Erkelens C, Lefeber AWM, Spijksma G, Heijden Rvd, 888 Verpoorte R (2009) Biosynthesis of salicylic acid in fungus elicited Catharanthus roseus 889 cells. Phytochemistry 70: 532-539

890 Nawrath C, Metraux J-P (1999) Salicylic acid inductional deficient mutants of Arabidopsis 891 express $P R-2$ and $P R-5$ and accumulate high levels of camalexin after pathogen inoculation. 892 Plant Cell 11: 1393-1404 
893 Nazar R, Iqbal N, Syeed S, Khan NA (2011) Salicylic acid alleviates decreases in 894 photosynthesis under salt stress by enhancing nitrogen and sulfur assimilation and 895 antioxidant metabolism differentially in two mungbean cultivars. J Plant Physiol 168: 807$896 \quad 815$

897 Nemeth M, Janda T, Horvath E, Paldi E, Szalai G (2002) Exogenous salicylic acid increases 898 polyamine content but may decrease drought tolerance in maize. Plant Sci 162: 569-574

899 Niederl S, Kirsch T, Riederer M, Schreiber L (1998) Co-permeability of ${ }^{3} \mathrm{H}-$ labeled water and $900{ }^{14}$ C-labeled organic acids across isolated plant cuticles investigating cuticular paths of 901 diffusion and predicting cuticular transpiration. Plant Physiol 116: 117-123

902 Nishimura N, Kitahata N, Seki M, Narusaka Y, Narusaka M, Kuromori T, Asami T, 903 Shinozaki K, Hirayama T (2005) Analysis of ABA hypersensitive germination2 revealed the 904 pivotal functions of PARN in stress response in Arabidopsis. Plant J 44: 972-984

905 Ogawa D, Nakajima N, Sano T, Tamaoki M, Aono M, Kubo A, Kanna M, Ioki M, Kamada $906 \mathrm{H}$, Saji H (2005) Salicylic acid accumulation under $\mathrm{O}_{3}$ exposure is regulated by ethylene in 907 tobacco plants. Plant Cell Physiol 46: 1062-1072

908 Ohashi Y, Murakami T, Mitsuhara I, Seo S (2004) Rapid down and upward translocation of 909 salicylic acid in tobacco plants. Plant Biotechnology 21: 95-101

910 Ondrasek G, Rengel Z, Veres S (2011) Soil salinisation and salt stress in crop production. In 911 A Shanker, B Venkateswarlu, eds, Abiotic stress in plants - mechanisms and adaptations. 912 InTech (ISBN: 978-953-307-394-1, DOI: 10.5772/22248), pp 171-190

913 Palmgren M, Nissen P (2010) P-type ATPases. Annual Review of Biophysics 40: 243-266

914 Pancheva TV, Popova LV (1997) Effect of salicylic acid on the synthesis of ribulose-1,5915 bisphosphate carboxylase/oxygenase in barley leaves. J Plant Physiol 220: 381-386

916 Pandolfi C, Pottosin I, Cuin T, Mancuso S, Shabala S (2010) Specificity of polyamine effects 917 on NaCl-induced ion flux kinetics and salt stress amelioration in plants. Plant Cell Physiol $918 \quad 51: 422-434$

919 Parida AK, Das AB (2005) Salt tolerance and salinity effects on plants: a review. Ecotoxicol 920 Environ Saf 60: 324-349 
921 Park SW, Kaimoyo E, Kumar D, Mosher S, Klessig DF (2007) Methyl salicylate is a critical mobile signal for plant systemic acquired resistance. Science 318: 113-116

923 Park SW, Liu PP, Forouhar F, Vlot AC, Tong L, Tietjen K, Klessig DF (2009) Use of a 924 synthetic salicylic acid analog to investigate the roles of methyl salicylate and its esterases in 925 plant disease resistance. J Biol Chem 284: 7307-7317

926 Poór P, Gémes K, Horváth F, Szepesi Á, Simon ML, Tari I (2011a) Salicylic acid treatment 927 via the rooting medium interferes with stomatal response, $\mathrm{CO}_{2}$ fixation rate and carbohydrate 928 metabolism in tomato, and decreases harmful effects of subsequent salt stress. Plant Biol 13: $929 \quad 105-114$

930 Poór P, Szopkó D, Tari I (2011b) Ionic homeostasis disturbance is involved in tomato cell 931 death induced by $\mathrm{NaCl}$ and salicylic acid. In Vitro Cell Dev Biol Plant 48: 377-382

932

933 Qadir M, Quillérou E, Nangia V, Murtaza G, Singh M, Thomas RJ, Drechsel P, Noble AD 934 (2014) Economics of salt-induced land degradation and restoration. Natural Res Forum 935 (DOI: 10.1111/1477-8947.12054)

936 Qi Y, Tsuda K, Joe A, Sato M, Nguyen LV, Glazebrook J, Alfano JR, Cohen JD, Katagiri F 937 (2010) A putative RNA-binding protein positively regulates salicylic acid-mediated 938 immunity in Arabidopsis. Molecular plant-microbe interactions 23: 1573-1583

939 Quan LJ, Zhang B, Shi WW, Li HY (2008) Hydrogen peroxide in plants: a versatile molecule 940 of the reactive oxygen species network. J Integr Plant Biol 50: 2-18

941 Rai V, Sharma S, SHARMA S (1986) Reversal of ABA-induced stomatal closure by 942 phenolic compounds. J Exp Bot 37: 129-134

943 Rajjou L, Belghazi M, Huguet R, Robin C, Moreau A, Job C, Job D (2006) Proteomic 944 investigation of the effect of salicylic acid on Arabidopsis seed germination and 945 establishment of early defense mechanisms. Plant Physiol 141: 910-923

946 Rao MV, Davis KR (1999) Ozone-induced cell death occurs via two distinct mechanisms in 947 Arabidopsis: the role of salicylic acid. Plant J 17: 603-614 
948 Rivas-San Vicente M, Plasencia J (2011) Salicylic acid beyond defence: its role in plant 949 growth and development. J Exp Bot 62: 3321-3338

950 Ross JR, Nam KH, D'Auria JC, Pichersky E (1999) S-adenosyl-L-methionine: salicylic acid 951 carboxyl methyltransferase, an enzyme involved in floral scent production and plant defense, 952 represents a new class of plant methyltransferases. Arch Biochem Biophys 367: 9-16

953 Rubio F, Gassmann W, Schroeder JI (1995) Sodium driven potassium uptake by the plant 954 potassium transporter $h k t 1$ and mutations conferring salt tolerance. Science 270: 1660-1663

955 Sahu BB, Shaw BP (2009) Salt-inducible isoform of plasma membrane $\mathrm{H}^{+}$-ATPase gene in 956 rice remains constitutively expressed in natural halophyte, Suaeda maritima. J Plant Physiol 957 166: 1077-1089

958 Sanders D (2000) Plant biology: The salty tale of Arabidopsis. Curr Biol 10: R486-R488

959 Sawada H, Shim I-S, Usui K (2006) Induction of benzoic acid 2-hydroxylase and salicylic 960 acid biosynthesis-modulation by salt stress in rice seedlings. Plant Sci 171: 263-270

961 Seskar M, Shulaev V, Raskin I (1998) Endogenous methyl salicylate in pathogen-inoculated 962 tobacco plants. Plant Physiol 116: 387-392

963 Shabala L, Cuin TA, Newman IA, Shabala S (2005) Salinity-induced ion flux patterns from 964 the excised roots of Arabidopsis sos mutants. Planta 222: 1041-1050

965 Shabala S (2009) Salinity and programmed cell death: unravelling mechanisms for ion 966 specific signalling. J Exp Bot 60: 709-712

967 Shabala S (2013) Learning from halophytes: physiological basis and strategies to improve 968 abiotic stress tolerance in crops. Ann Bot 112: 1209-1221

969 Shabala S, Cuin TA (2008) Potassium transport and plant salt tolerance. Physiol Plant 133: $970 \quad 651-669$

971 Shabala S, Cuin TA, Prismall L, Nemchinov LG (2007) Expression of animal CED-9 anti972 apoptotic gene in tobacco modifies plasma membrane ion fluxes in response to salinity and 973 oxidative stress. Planta 227: 189-197 
974 Shabala S, Demidchik V, Shabala L, Cuin TA, Smith SJ, Miller AJ, Davies JM, Newman IA 975 (2006) Extracellular $\mathrm{Ca}^{2+}$ ameliorates $\mathrm{NaCl}$-induced $\mathrm{K}^{+}$loss from Arabidopsis root and leaf 976 cells by controlling plasma membrane $\mathrm{K}^{+}$-permeable channels. Plant Physiol 141: 1653-1665

977 Shabala S, Shabala L, Van Volkenburgh E (2003) Effect of calcium on root development and 978 root ion fluxes in salinised barley seedlings. Funct Plant Biol 30: 507-514

979 Shakirova FM (2003) Changes in the hormonal status of wheat seedlings induced by salicylic 980 acid and salinity. Plant Sci 164: 317-322

981 Shi HZ, Ishitani M, Kim CS, Zhu JK (2000) The Arabidopsis thaliana salt tolerance gene 982 SOS1 encodes a putative $\mathrm{Na}^{+} / \mathrm{H}^{+}$antiporter. Proceedings of the National Academy of 983 Sciences 97: 6896-6901

984 Shirasu K, Nakajima H, Rajasekhar VK, Dixon RA, Lamb C (1997) Salicylic acid potentiates 985 an agonist-dependent gain control that amplifies pathogen signals in the activation of defense 986 mechanisms. Plant Cell 9: 261-270

987 Shulaev V, Silverman P, Raskin I (1997) Airborne signalling by methyl salicylate in plant 988 pathogen resistance. Nature 385: 718-721

989 Smethurst CF, Rix K, Garnett T, Auricht G, Bayart A, Lane P, Wilson SJ, Shabala S (2008) 990 Multiple traits associated with salt tolerance in lucerne: revealing the underlying cellular 991 mechanisms. Funct Plant Biol 35: 640-650

992 Song JT (2006) Induction of a salicylic acid glucosyltransferase, AtSGT1, is an early disease 993 response in Arabidopsis thaliana. Mol Cells 22: 233-238

994 Song JT, Koo YJ, Seo HS, Kim MC, Choi YD, Kim JH (2008) Overexpression of AtSGT1, 995 an Arabidopsis salicylic acid glucosyltransferase, leads to increased susceptibility to 996 Pseudomonas syringae. Phytochemistry 69: 1128-1134

997 Stevens J, Senaratna T, Sivasithamparam K (2006) Salicylic acid induces salinity tolerance in 998 tomato (Lycopersicon esculentum cv. Roma): Associated changes in gas exchange, water 999 relations and membrane stabilisation. Plant Growth Regul 49: 77-83 
1000 Strawn MA, Marr SK, Inoue K, Inada N, Zubieta C, Wildermuth MC (2007) Arabidopsis 1001 isochorismate synthase functional in pathogen-induced salicylate biosynthesis exhibits 1002 properties consistent with a role in diverse stress responses. J Biol Chem 282: 5919-5933

1003 Sun W, Xu X, Zhu H, Liu A, Liu L, Li J, Hua X (2010) Comparative transcriptomic profiling 1004 of a salt-tolerant wild tomato species and a salt-sensitive tomato cultivar. Plant Cell Physiol 1005 51: 997-1006

1006 Szepesi A, Csiszar J, Gemes K, Horvath E, Horvath F, Simon ML, Tari I (2009) Salicylic 1007 acid improves acclimation to salt stress by stimulating abscisic aldehyde oxidase activity and 1008 abscisic acid accumulation, and increases $\mathrm{Na}^{+}$content in leaves without toxicity symptoms in 1009 Solanum lycopersicum L. J Plant Physiol 166: 914-925

1010 Szepesi A, Poór P, Gémes K, Horváth E, Tari I (2008) Influence of exogenous salicylic acid 1011 on antioxidant enzyme activities in the roots of salt stressed tomato plants. Acta Biologica 1012 Szegediensis 52: 199-200

1013 Tester M, Langridge P (2010) Breeding technologies to increase crop production in a 1014 changing world. Science 327: 818-22

1015 Tester M, Davenport R (2003) $\mathrm{Na}^{+}$tolerance and $\mathrm{Na}^{+}$transport in higher plants. Ann Bot 91: $1016 \quad 503-527$

1017 Tyerman SD (2002) Nonselective cation channels. Multiple functions and commonalities. 1018 Plant Physiol 128: 327-328

1019 Tyerman SD, Skerrett IM (1999) Root ion channels and salinity. Scientia Horticulturae 78: $1020 \quad 175-235$

1021 Tyerman SD, Skerrett M, Garrill A, Findlay GP, Leigh RA (1997) Pathways for the 1022 permeation of $\mathrm{Na}^{+}$and $\mathrm{Cl}^{-}$into protoplasts derived from the cortex of wheat roots. $\mathrm{J}$ Exp Bot 1023 48: 459-480

1024 Uzunova A, Popova L (2000) Effect of salicylic acid on leaf anatomy and chloroplast 1025 ultrastructure of barley plants. Photosynthetica 38: 243-250 
1026 Verberne MC, Verpoorte R, Bol JF, Mercado-Blanco J, Linthorst HJM (2000) 1027 Overproduction of salicylic acid in plants by bacterial transgenes enhances pathogen resistance. Nat Biotechnol 18: 779-783

1029 Vidhyasekaran P (2015) Salicylic Acid Signaling in Plant Innate Immunity. In Plant 1030 Hormone Signaling Systems in Plant Innate Immunity, Vol 2. Springer Netherlands, pp 27$1031 \quad 122$

1032 Vlot AC, Dempsey DMA, Klessig DF (2009) Salicylic acid, a multifaceted hormone to 1033 combat disease. Annu Rev Phytopathol 47: 177-206

1034 Vlot AC, Liu P-P, Cameron RK, Park S-W, Yang Y, Kumar D, Zhou F, Padukkavidana T, 1035 Gustafsson C, Pichersky E, Klessig DF (2008) Identification of likely orthologs of tobacco 1036 salicylic acid-binding protein 2 and their role in systemic acquired resistance in Arabidopsis thaliana. Plant J 56: 445-456

Wildermuth MC, Dewdney J, Wu G, Ausubel FM (2001) Isochorismate synthase is required to synthesize salicylic acid for plant defence. Nature 414: 562-565

1040 Wu C-A, Yang G-D, Meng Q-W, Zheng C-C (2004) The cotton GhNHX1 gene encoding a novel putative tonoplast $\mathrm{Na}^{+} / \mathrm{H}^{+}$antiporter plays an important role in salt stress. Plant Cell Physiol 45: 600-607

1043 Wu Y, Zhang D, Chu JY, Boyle P, Wang Y, Brindle ID, De Luca V, Després C (2012) The 1044 Arabidopsis NPR1 protein is a receptor for the plant defense hormone salicylic acid. Cell 1045 Reports 1: 639-647

1046 Xia J, Zhao H, Liu W, Li L, He Y (2009) Role of cytokinin and salicylic acid in plant growth 1047 at low temperatures. Plant Growth Regul 57: 211-221

1048 Xie Z, Zhang Z-L, Hanzlik S, Cook E, Shen QJ (2007) Salicylic acid inhibits gibberellin1049 induced alpha-amylase expression and seed germination via a pathway involving an abscisic1050 acid-inducible WRKY gene. Plant Mol Biol 64: 293-303

1051 Yalpani N, Silverman P, Wilson TM, Kleier DA, Raskin I (1991) Salicylic acid is a systemic 1052 signal and an inducer of pathogenesis-related proteins in virus-infected tobacco. Plant Cell 3: 1053 809-818 
1054 Yang YN, Qi M, Mei CS (2004) Endogenous salicylic acid protects rice plants from 1055 oxidative damage caused by aging as well as biotic and abiotic stress. Plant J 40: 909-919

1056 Yasuda M, Ishikawa A, Jikumaru Y, Seki M, Umezawa T, Asami T, Maruyama-Nakashita A, 1057 Kudo T, Shinozaki K, Yoshida S (2008) Antagonistic interaction between systemic acquired 1058 resistance and the abscisic acid-mediated abiotic stress response in Arabidopsis. Plant Cell 1059 20: 1678-1692

1060 Yildirim E, Turan M, Guvenc I (2008) Effect of foliar salicylic acid applications on growth, 1061 chlorophyll, and mineral content of cucumber grown under salt stress. J Plant Nutr 31: 5931062612

1063 Zhang HX, Blumwald E (2001) Transgenic salt-tolerant tomato plants accumulate salt in 1064 foliage but not in fruit. Nat Biotechnol 19: 765-768

1065 Zhang HX, Hodson JN, Williams JP, Blumwald E (2001) Engineering salt-tolerant Brassica 1066 plants: Characterization of yield and seed oil quality in transgenic plants with increased 1067 vacuolar sodium accumulation. Proc Natl Acad Sci 98: 12832-12836

1068 Zhang X, Chen S, Mou Z (2010) Nuclear localization of NPR1 is required for regulation of 1069 salicylate tolerance, isochorismate synthase 1 expression and salicylate accumulation in 1070 Arabidopsis. J Plant Physiol 167: 144-148

1071 Zhu JK (2002) Salt and drought stress signal transduction in plants. Annu Rev Plant Biol 53: $1072 \quad 247-273$

1073 Zhu JK (2003) Regulation of ion homeostasis under salt stress. Curr Opin Plant Biol 6: 4411074445

1075 Zörb C, Noll A, Karl S, Leib K, Yan F, Schubert S (2005) Molecular characterization of $1076 \mathrm{Na}^{+} / \mathrm{H}^{+}$antiporters (ZmNHX) of maize (Zea mays L.) and their expression under salt stress. J 1077 Plant Physiol 162: 55-66

1078

1079

1080 
1082<smiles>N[C@@H](Cc1ccccc1)C(=O)O</smiles>

L-Phenylalanine<smiles>O=C(O)/C=C/c1ccccc1</smiles>

trans-Cinnamic acid<smiles>O=C(O)c1ccccc1</smiles>

Benzoic acid<smiles>C=C(O[C@H]1C=C(C(=O)O)C=C[C@@H]1O)C(=O)O</smiles><smiles>O=C(O)c1ccccc1OC(Cl)(Cl)Cl</smiles>

Salicylic acid O- $\beta$-glucoside<smiles>C=C(O[C@H]1CC=CC(C(=O)O)=C1O)C(=O)O</smiles><smiles>O=C(O[Ge])c1ccccc1O</smiles>
Isochorismate Salicyloyl glucose ester<smiles>O=C(O)c1ccccc1O</smiles>

Salicylic acid<smiles>COC(=O)c1ccccc1O</smiles>

Methyl salicylate

Figure 1: Chemical structure of phenolic compounds that participates in salicylic acid (o-hydroxybenzoic acid) biosynthesis and metabolism. 


\section{Apoplast}

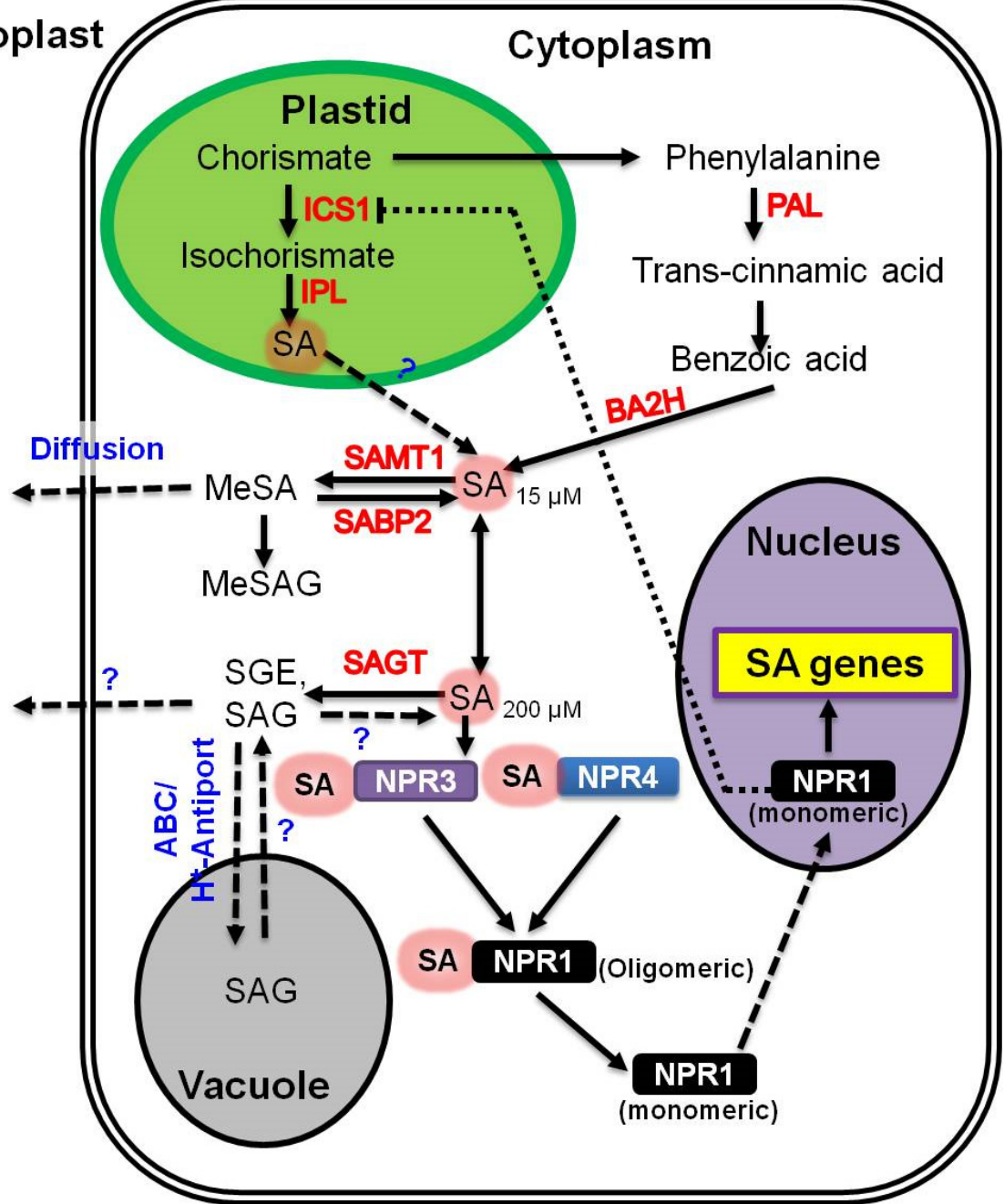

Figure 1: SA biosynthesis, metabolism, homeostasis, transport and signalling during biotic and abiotic stresses. Enzymes involved in SA production and metabolism are shown in red fonts. $\mathrm{BA} 2 \mathrm{H}=$ benzoic-acid-2-hydroxylase; $\mathrm{ICS} 1=$ isochorismate synthase 1; IPL= isochorismate pyruvate-lyase; $\mathrm{PAL}=$ phenylalanine ammonia-lyase; SABP2 $=$ SA-binding protein 2; SAGT $=$ SA glycosyltransferase; SAMT1 $=$ SA carboxyl methyltransferase . Concentrations shown are $K_{m}$ values of SAMT1 $(15 \mu \mathrm{M})$ and SAGT $(20 \mu \mathrm{M})$. Dashed lines with arrows indicate transport across the membranes. Blue text denotes mode of transport. Question marks denote unidentified mechanisms. ABC denotes ATP-binding cassette transport protein. SA surrounded by pink colour indicates free SA. SA conjugated forms are $\mathrm{MeSA}=$ methyl salicylate; MeSAG= methyl SA O-ß-glucose; SAG= SA O- - -glucoside; $\mathrm{SGE}=$ salicyloyl glucose ester. SA-binding receptors are depicted in boxes. NPR1/2/3= nonexpresser of PR (pathogenesis-related) proteins 1/2/3. 'Oligomeric' means the oxidised form of NPR1, whereas 'monomeric' denotes reduced form of NPR1. Dotted line connecting NPR1 in the nucleus and ICS1 depicts the inhibition of ICS1 following activation of defence response. 




1126

Figure 3. Thematic diagram of "self-amplifying feedback loop" between salicylic acid 1128 (SA) and hydrogen peroxide $\left(\mathrm{H}_{2} \mathrm{O}_{2}\right)$. 
1130

1131

1132

1133

1134

1135

1136

1137

1138

1139

1140

1141

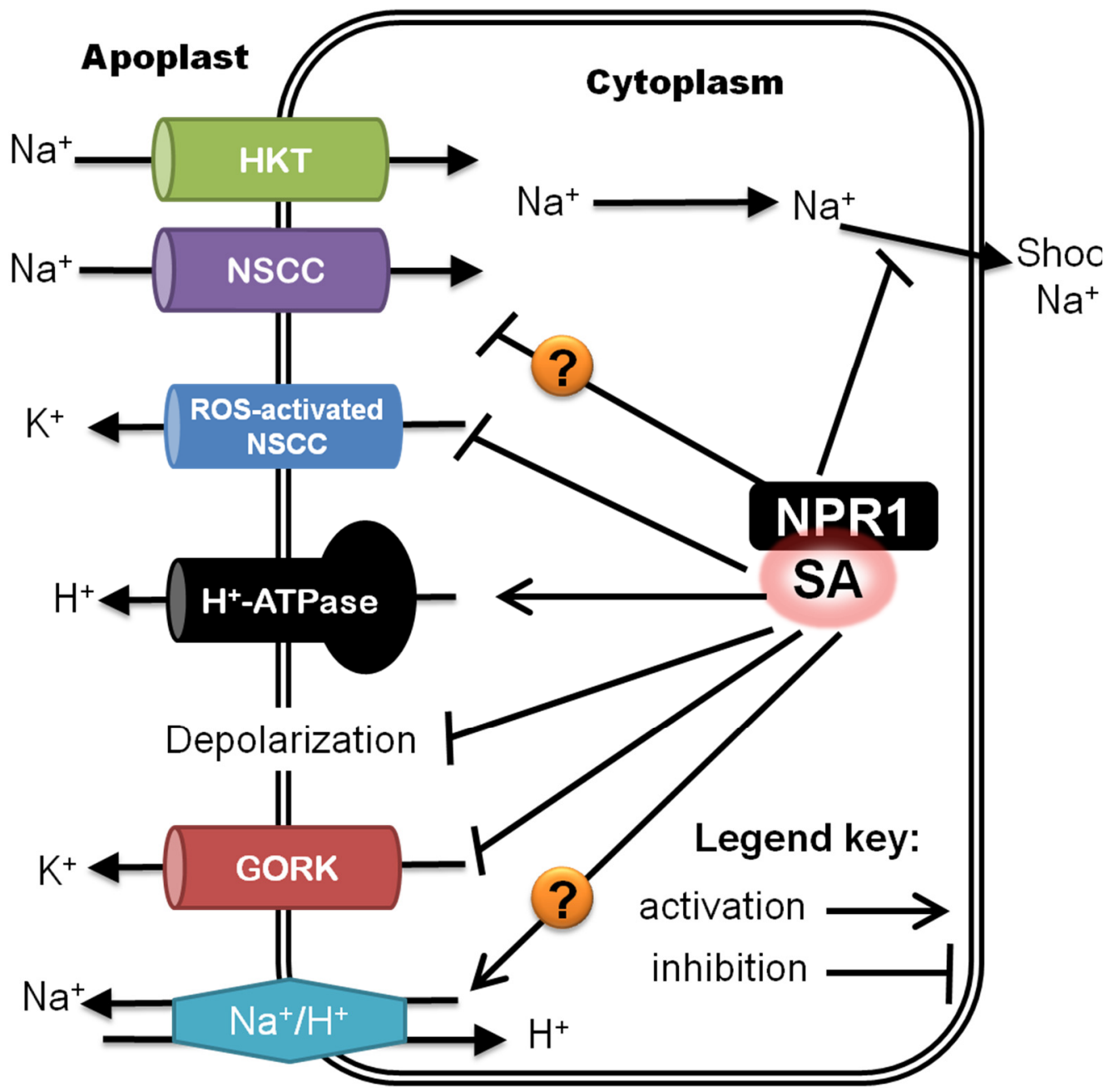

1142

1143

1144

1145

1146

1147 Figure 4: Generalised model explaining SA-mediated NPR1-depandent salt tolerance 1148 mechanisms in plants. HKT-High affinity $\mathrm{K}^{+}$transporter; NSCC, non-selective cation 1149 channels; ROS, reactive oxygen species; GORK, guard cell outward-rectifying $\mathrm{K}^{+}$channel; 1150 NPR1, non-expresser of pathogenous-related gene 1. A question mark denotes pending 1151 pharmacological experiments to confirm the role. 